ARTICLE

https://doi.org/10.1038/s41467-019-08532-3

\title{
Exceptionally active iridium evolved from a pseudo- cubic perovskite for oxygen evolution in acid
}

Yubo Chen ${ }^{1,2,3}$, Haiyan $\mathrm{Li}^{1,3}$, Jingxian Wang ${ }^{1}$, Yonghua $\mathrm{Du}^{4}$, Shibo $\mathrm{Xi}^{4}$, Yuanmiao Sun ${ }^{1}$, Matthew Sherburne ${ }^{5,6}$, Joel W. Ager III (1) 5,6, Adrian C. Fisher ${ }^{2,7} \&$ Zhichuan J. Xu (D) 1,2,3,8

Exploring robust catalysts for water oxidation in acidic electrolyte is challenging due to the limited material choice. Iridium (Ir) is the only active element with a high resistance to the acid corrosion during water electrolysis. However, Ir is rare, and its large-scale application could only be possible if the intrinsic activity of Ir could be greatly enhanced. Here, a pseudocubic $\mathrm{SrCo}_{0.9} \mathrm{Ir}_{0.1} \mathrm{O}_{3-\delta}$ perovskite, containing corner-shared IrO6 octahedrons, is designed. The $\mathrm{Ir}$ in the $\mathrm{SrCO}_{0.9} \mid \mathrm{r}_{0.1} \mathrm{O}_{3-\delta}$ catalyst shows an extremely high intrinsic activity as reflected from its high turnover frequency, which is more than two orders of magnitude higher than that of $\mathrm{IrO}_{2}$. During the electrochemical cycling, a surface reconstruction, with $\mathrm{Sr}$ and $\mathrm{Co}$ leaching, over $\mathrm{SrCo}_{0.9} \mathrm{Ir}_{0.1} \mathrm{O}_{3-\delta}$ occurs. Such reconstructed surface region, likely contains a high amount of structural domains with corner-shared and under-coordinated $\mathrm{IrO}_{x}$ octahedrons, is responsible for the observed high activity.

\footnotetext{
${ }^{1}$ School of Material Science and Engineering, Nanyang Technological University, 50 Nanyang Avenue, Singapore 639798, Singapore. ${ }^{2}$ The Cambridge Centre for Advanced Research and Education in Singapore, 1 CREATE Way, Singapore 138602, Singapore. ${ }^{3}$ Solar Fuels Laboratory, Nanyang Technological University, 50 Nanyang Avenue, Singapore 639798, Singapore. ${ }^{4}$ Institute of Chemical and Engineering Sciences, A*STAR, 1 Pesek Road, Singapore 627833, Singapore. ${ }^{5}$ Department of Materials Science and Engineering, University of California at Berkeley, Berkeley, CA 94720, USA. ${ }^{6}$ Berkeley Educational Alliance for Research in Singapore Ltd., 1 CREATE Way, Singapore 138602, Singapore. ${ }^{7}$ Department of Chemical Engineering, University of Cambridge, Cambridge CB2 3RA, UK. ${ }^{8}$ Energy Research Institute @ Nanyang Technological University, 50 Nanyang Avenue, Singapore 639798, Singapore. Correspondence and requests for materials should be addressed to Z.J.X. (email: xuzc@ntu.edu.sg)
} 
T he electricity from renewable energy sources, such as wind and solar power, has been showing a gradual proportional increase in global energy infrastructure ${ }^{1}$. However, due to the intermittent availability, the storage of the electric energy by these sources becomes pivotal. The conversion of the electricity into hydrogen fuel is expected to be one of the most efficient storage ways due to the high energy density of hydrogen fuel. Water electrolysis is a promising strategy to realize such energy conversion. The alkaline condition has been popular for industrial water electrolysis, while the acidic electrolyte condition is not. This is mainly due to the limited choices of robust anode catalysts in acidic condition during the oxygen evolution reaction (OER). In fact, the acidic condition offers a high proton concentration and thus enables much faster reaction kinetics of hydrogen production ${ }^{2,3}$. An ideal anode catalyst in acid should exhibit both high catalytic activity and high tolerance to the severe acidic corrosion at a high anodic potential. To date, the iridium oxides have been found high in stability in harsh acidic environment ${ }^{4,5}$. Due to the high cost and scarcity of Ir, great efforts have been made to develop novel Ir-based materials for water oxidation with high efficiency, e.g., a high activity normalized to the material surface area (intrinsic activity) and, more importantly, a high turnover frequency (TOF) for $\operatorname{Ir}^{6-11}$.

Recently, several Ir-based perovskites were reported as highly active catalysts for OER ${ }^{12-15}$. The perovskite is a type of oxide with a general formula of $\mathrm{ABO}_{3}$, where $\mathrm{A}$ represents alkalineearth-metal or lanthanide and $\mathrm{B}$ represents active transition metals. Among these perovskite catalysts, a $\mathrm{SrIrO}_{3}$ perovskite, with reconstructed surface was found with the highest intrinsic activity (normalized to its surface area) for catalyzing OER in acidic environment to date ${ }^{13}$. Nevertheless, the synthesis of such $\mathrm{SrIrO}_{3}$ catalysts requires special tools or conditions, such as a pulse laser deposition (PLD) equipment ${ }^{16}$ or a high pressure $(\sim 5 \mathrm{GP})$ for solid state synthesis ${ }^{17}$, which could hinder the practical application of such catalyst. In addition, the key surface reconstruction step in this $\mathrm{PLD}-\mathrm{SrIrO}_{3}$ is likely time-consuming because a $\sim 30 \mathrm{~h}$ electrochemical activation process is required.

Here, we design a pseudo-cubic $\mathrm{SrCo}_{0.9} \mathrm{Ir}_{0.1} \mathrm{O}_{3-\delta}$ material with an orthorhombic structure. In this design, the Ir and Co co-share the octahedral site and all octahedrons are corner shared. To form a comparison, we investigate a monoclinic $\mathrm{SrIrO}_{3}\left(\mathrm{~m}-\mathrm{SrIrO}_{3}\right)$ perovskite, which adopts a highly distorted $6 \mathrm{H} \mathrm{BaTiO}_{3}$ structure with mixed corner-shared and face-shared IrO6 octahedrons ${ }^{18,19}$. We show that the intrinsic activity (TOF) of Ir from $\mathrm{SrCo}_{0.9} \mathrm{Ir}_{0.1} \mathrm{O}_{3-\delta}$ is approximately two orders of magnitude higher than the $\mathrm{m}-\mathrm{SrIrO}_{3}$ and more than one order of magnitude higher than the benchmark PLD-SrIrO $\mathrm{SrCo}_{0.9} \mathrm{Ir}_{0.1} \mathrm{O}_{3-\delta}$ surface during electrochemical tests. As a result, a highly active surface $\mathrm{IrO}_{x}$ layer likely contains a high amount of corner-shared and under-coordinated $\mathrm{IrO}_{x}$ octahedrons without long-range ordering, and is responsible for the observed superior activity of $\mathrm{SrCo}_{0.9} \mathrm{Ir}_{0.1} \mathrm{O}_{3-\delta}$.

\section{Results}

Structure characterization. Figure $1 \mathrm{a}-\mathrm{c}$ shows the crystal structures of PLD-SrIrO ${ }_{3}$, pseudo-cubic $\mathrm{SrCo}_{0.9} \mathrm{Ir}_{0.1} \mathrm{O}_{3-\delta}$, and $\mathrm{m}-\mathrm{SrIrO}_{3}$. In PLD-SrIrO $\mathrm{Sn}_{3}$ and pseudo-cubic $\mathrm{SrCo}_{0.9} \mathrm{Ir}_{0.1} \mathrm{O}_{3-\delta}$, all $\mathrm{IrO} 6$ octahedrons are corner-shared. Nevertheless, in m$\mathrm{SrIrO}_{3}$, corner-shared and face-shared IrO6 octahedrons are alternatively arranged. Both $\mathrm{m}-\mathrm{SrIrO}_{3}$ and $\mathrm{SrCo}_{0.9} \mathrm{Ir}_{0.1} \mathrm{O}_{3-\delta}$ samples were synthesized with a classical solid state method, which is easily accessible for large scale preparation. Figure $1 \mathrm{~d}$ includes the scanning electron microscope (SEM) images from $\mathrm{m}-\mathrm{SrIrO}_{3}$ and $\mathrm{SrCo}_{0.9} \mathrm{Ir}_{0.1} \mathrm{O}_{3-\delta}$ samples. The corresponding Brunauer-Emmett-Teller (BET) surface area for these two samples are also presented. The $\mathrm{SrCo}_{0.9} \mathrm{Ir}_{0.1} \mathrm{O}_{3-\delta}$ has a lower BET surface area due to its relative large particles. $\mathrm{A} \mathrm{m}-\mathrm{SrIrO}_{3}$ with a space group (SG) of C $2 / c$ and a $\mathrm{SrCo}_{0.9} \mathrm{Ir}_{0.1} \mathrm{O}_{3-\delta}$ with SG of $\mathrm{P}$ nma are confirmed based on their X-ray diffraction (XRD) patterns (the refined results are shown in Fig. 1e and Supplementary Table 1). Figure 1f, g presents HRTEM images taken from $\mathrm{m}$-SrIrO${ }_{3}$ and $\mathrm{SrCo}_{0.9} \mathrm{Ir}_{0.1} \mathrm{O}_{3-\delta}$. The corresponding inverse fast Fourier transformed (FFT) images are taken from white square box regions. The measured interplanar distances from inverse FFT images correspond well with the results from XRD refinement, which are in brackets. Selected area electron diffraction (SAED) patterns are also presented. All patterns can be well indexed based on the XRD refinement results, indicating the formation of $\mathrm{m}-\mathrm{SrIrO}_{3}$ and $\mathrm{SrCo}_{0.9} \mathrm{Ir}_{0.1} \mathrm{O}_{3-\delta}$ with high purity.

Activity evaluation. The activities of $\mathrm{SrCo}_{0.9} \mathrm{Ir}_{0.1} \mathrm{O}_{3-\delta}, \mathrm{m}-\mathrm{SrIrO}_{3}$ and commercial $\mathrm{IrO}_{2}$ for the OER were then evaluated in a perchloric acid solution $(0.1 \mathrm{M}, \mathrm{pH}=1.08)$. The measured specific activity $\left(\mathrm{mA} \mathrm{cm}^{-2}\right.$ normalized to BET surface area), representing the intrinsic activity of a catalyst ${ }^{20}$, is shown in Fig. $1 \mathrm{~h}$. The activity for the PLD-SrIrO 3 prepared with PLD method from literature is also presented for comparison ${ }^{13}$. The calculated specific activity of $\mathrm{IrO}_{2}$ is similar to the previously reported values? ${ }^{7}$. A higher specific activity, approximately one order of magnitude higher than that of $\mathrm{IrO}_{2}$, is obtained from the $\mathrm{m}-\mathrm{SrIrO}_{3}$. For instance, at a potential of $1.5 \mathrm{~V}$ (vs. RHE), a specific current density of $\sim 1 \times 10^{-2} \mathrm{~mA} \mathrm{~cm}^{-2}$ and $\sim 0.2 \mathrm{~mA} \mathrm{~cm}^{-2}$ is recorded for $\mathrm{IrO}_{2}$ and $\mathrm{m}$-SrIrO $\mathrm{S}_{3}$, respectively. However, such activity is much inferior to that of the PLD-SrIrO ${ }_{3}$. Moreover, different from the reported $\mathrm{PLD}-\mathrm{SrIrO}_{3}$ catalyst, the $\mathrm{m}-\mathrm{SrIrO}_{3}$ did not show a gradually increased activity during the successive test (Supplementary Figure 1). As a result, the specific activity of the $\mathrm{m}-\mathrm{SrIrO}_{3}$ is more than one order of magnitude lower than that from the PLD-SrIrO catalyst (stabilized activity at $2 \mathrm{~h}$ ). This activity difference indicates that the pseudo-cubic structure is a key factor to determine the intrinsic activity of $\mathrm{SrIrO}_{3}$. On the other hand, regardless of the low Ir atom ratio in the lattice, the specific activity of $\mathrm{SrCo}_{0.9} \mathrm{Ir}_{0.1} \mathrm{O}_{3-\delta}$ is more than one order of magnitude higher than that from $\mathrm{m}$-SrIrO and comparable with the reported initial activity of PLD-SrIrO ${ }_{3}$. Interestingly, such specific activity is just 2-4 times lower than the final specific activity of PLD-SrIrO activity of $\mathrm{Ir}$ over the surface of $\mathrm{SrCo}_{0.9} \mathrm{Ir}_{0.1} \mathrm{O}_{3-\delta}$ is higher than that of Ir over the surface of PLD-SrIrO ${ }_{3}$. We caution that the Co in $\mathrm{SrCo}_{0.9} \mathrm{Ir}_{0.1} \mathrm{O}_{3-\delta}$ does not contribute to the observed superior activity of $\mathrm{SrCo}_{0.9} \mathrm{Ir}_{0.1} \mathrm{O}_{3-\delta}$ for its high solubility in the acidic electrolyte (Supplementary Figure 2). Additionally, as discussed in the following sections, a rapid dissolution of $\mathrm{Sr}$ and $\mathrm{Co}$ is expected in acidic electrolytes. The stable activity of $\mathrm{SrCo}_{0.9} \mathrm{Ir}_{0.1} \mathrm{O}_{3-\delta}$ during cycling test, shown in Supplementary Figure 2, also confirms that the measured OER current contributed by $\mathrm{Sr}$ and Co leaching is negligible. In addition, an estimated maximum current due to $\mathrm{Sr}$ and Co leaching in initial 5 cycles is more than two orders of magnitude lower than the measured OER current from $\mathrm{SrCo}_{0.9} \mathrm{Ir}_{0.1} \mathrm{O}_{3-\delta}$ (see the estimation of the current due to $\mathrm{Sr}$ and $\mathrm{Co}$ leaching in the Methods). Figure 1i presents the TOF of Ir from $\mathrm{IrO}_{2}, \mathrm{~m}-\mathrm{SrIrO}_{3}$, and $\mathrm{SrCo}_{0.9} \mathrm{Ir}_{0.1} \mathrm{O}_{3-\delta}$. Three cases, including $\mathrm{Ir}$ at outermost surfaces (upper limit), of Ir from reconstructed surface regions (the surface reconstruction over catalysts will be discussed later) and all Ir from the bulk (lower limit), were considered for TOF calculations. Calculation details are presented in Methods. Among them, the TOF of Ir by considering the effect of surface reconstruction should be the most reliable for comparing the intrinsic activity of Ir from different materials. From Fig. 1i, at an overpotential of $270 \mathrm{mV}$ (1.5 V vs. RHE), the $\mathrm{Ir}$ in $\mathrm{SrCo}_{0.9} \mathrm{Ir}_{0.1} \mathrm{O}_{3-\delta}$ is found with a high TOF of $2.56 \pm 0.15 \mathrm{~s}^{-1}$, which is more than 
a

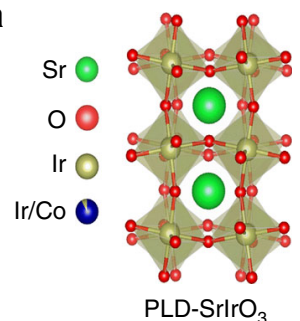

b

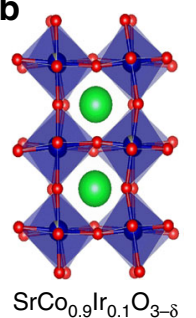

c

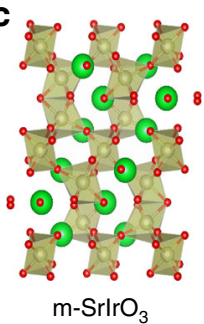

d

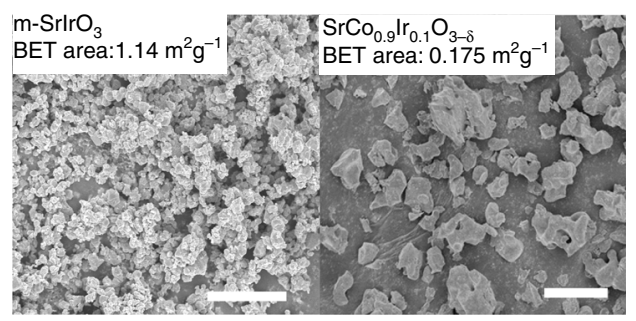

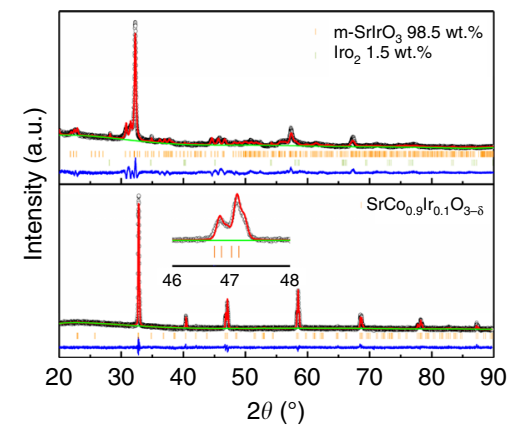

f

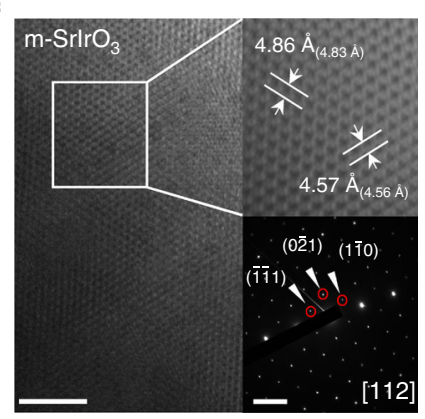

g

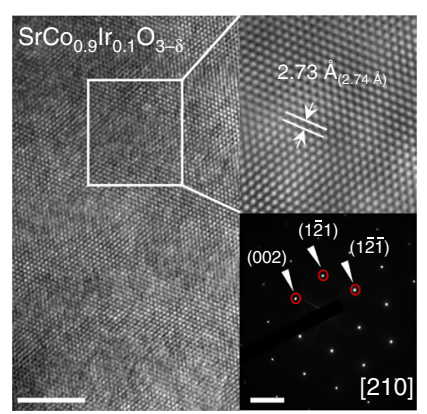

h

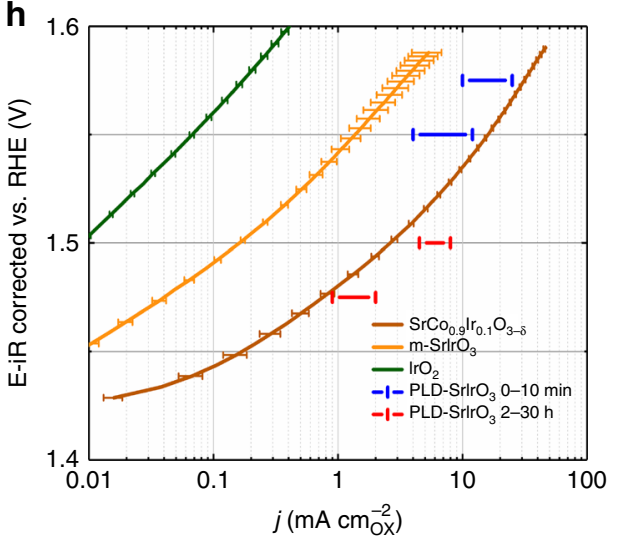

i

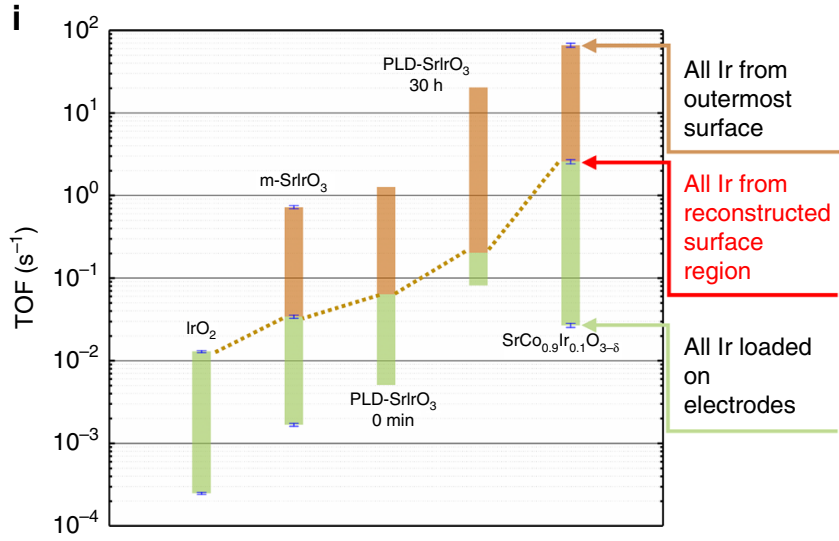

Fig. 1 Crystal structure and OER activity of $\mathrm{SrCO}_{0.9} \mathrm{Ir}_{0.1} \mathrm{O}_{3-\delta}$. Crystal structures of a PLD-SrlrO ${ }_{3}^{17}$, b pseudo-cubic $\mathrm{SrCO}_{0.9} \mathrm{Ir}_{0.1} \mathrm{O}_{3-\delta}$, and $\mathbf{c} \mathrm{m}-\mathrm{SrlrO}_{3}$. d scanning electron microscopy (SEM) images of as-prepared $\mathrm{m}-\mathrm{SrlrO}_{3}$ (scale bar, $5 \mu \mathrm{m}$ ) and $\mathrm{SrCo}_{0.9} \mathrm{lr}_{0.1} \mathrm{O}_{3-\delta}$ (scale bar, $20 \mu \mathrm{m}$ ). e Rietveld refinement of $\mathrm{X}$-ray diffraction (XRD) patterns of as-prepared $\mathrm{m}-\mathrm{SrlrO}_{3}$ and $\mathrm{SrCo}_{0.9} \mathrm{Ir}_{0.1} \mathrm{O}_{3-\delta} ;$ minor $\mathrm{IrO}_{2}$ phase is found in the as-prepared $\mathrm{m}-\mathrm{SrlrO}_{3}$ and a single $\mathrm{SrCo}_{0.9} \mathrm{Ir}_{0.1} \mathrm{O}_{3-\delta}$ phase is obtained; the reliability factors for $\mathrm{m}-\mathrm{SrlrO}_{3}$ are $R_{\mathrm{wp}}=8.41 \%, R_{\mathrm{p}}=6.47 \%, x^{2}=3.398$; the reliability factors for the $\mathrm{SrCo}_{0.9} \mathrm{Ir}_{0.1} \mathrm{O}_{3-\delta}$ are $R_{\mathrm{wp}}=2.52 \%$, $R_{\mathrm{p}}=1.95 \%, x^{2}=1.521$. During the refinement, the structure parameters (space group: $\mathrm{C} 2 / \mathrm{c}$ ) of $\mathrm{SrlrO}_{3}$ reported by Qasim is used and only the lattice parameters of $\mathrm{m}-\mathrm{SrlrO}_{3}$ were refined ${ }^{19}$. The refined lattice parameters for $\mathrm{m}-\mathrm{SrlrO}_{3}$ are $a=5.5865(8), b=9.648(1), c=14.153(1)$, alpha $=90^{\circ}, b e t a=$ 93.048(9) ${ }^{\circ}$, and gamma $=90^{\circ}$. The detailed structure parameters for $\mathrm{SrCo}_{0.9} \mathrm{Ir}_{0.1} \mathrm{O}_{3-\delta}$ are presented in Supplementary Table 1. A refined occupancy ratio for Ir in $\mathrm{SrCO}_{0.9} \mid \mathrm{r}_{0.1} \mathrm{O}_{3-\delta}$ is 0.093 , which confirms the Ir has been successfully doped in the Co site. $\mathbf{f}$, $\mathbf{g}$ High-resolution transmission electron microscopy (HRTEM) images taken from $\mathrm{m}-\mathrm{SrlrO}_{3}$ and $\mathrm{SrCo}_{0.9} \mathrm{Ir}_{0.1} \mathrm{O}_{3-\delta}$ (scale bar, $5 \mathrm{~nm}$ ). The corresponding inverse fast Fourier transformed (FFT) images are taken from white square box regions (scale bar, $51 / \mathrm{nm}$ ). The measured interplanar distances from inverse FFT images correspond well with the XRD refinement results, which are in brackets. The selected area electron diffraction (SAED) patterns from corresponding zone axes are presented and indexed based on the data from XRD refinement. $\mathbf{h}$ Specific OER activities of $\mathrm{IrO}_{2}, \mathrm{~m}-\mathrm{SrlrO}_{3}$, and $\mathrm{SrCo}_{0.9} \mathrm{Ir}_{0.1} \mathrm{O}_{3-\delta}$ in $0.1 \mathrm{M} \mathrm{HClO}_{4}$. The specific OER activities of PLD-SrlrO in $0.5 \mathrm{M}$ $\mathrm{H}_{2} \mathrm{SO}_{4}$ are from the literature ${ }^{13}$. For the activity of PLD-SrlrO $\mathrm{O}_{3}$ samples, the activity evolution within 0-10 min and 2-30 h are shown as bars. i Calculated range for turnover frequency (TOFs) of Ir from different samples at an overpotential of $270 \mathrm{mV}$. The TOFs are calculated by assuming Ir at outermost surfaces (upper limit), Ir from reconstructed surface regions (the intermediate value) and all Ir from the bulk (lower limit) are involved in catalyzing water oxidation. The error bars correspond to the s.d

10 times and $\sim 75$ times higher than $\mathrm{PLD}-\mathrm{SrIrO}_{3}\left(\sim 0.2 \mathrm{~s}^{-1}\right)$ and $\mathrm{m}-\mathrm{SrIrO}_{3}\left(0.034 \pm 0.001 \mathrm{~s}^{-1}\right)$, respectively. It confirmed that the observed superior activity of $\mathrm{SrCo}_{0.9} \mathrm{Ir}_{0.1} \mathrm{O}_{3-\delta}$ is attributed to the formation of highly active surface Ir species.

Surface reconstruction. For $\mathrm{IrO}_{2}$, it has been reported with a high resistance to acidic corrosion ${ }^{21}$. However, it is unlikely that $\mathrm{m}$-SrIrO $\mathrm{S}_{3}$ and $\mathrm{SrCo}_{0.9} \mathrm{Ir}_{0.1} \mathrm{O}_{3-\delta}$ can keep their original structure in strong acidic condition due to the thermodynamic instability of
$\mathrm{Sr}$ and Co. The surface structure evolution of $\mathrm{m}-\mathrm{SrIrO}_{3}$ and $\mathrm{SrCo}_{0.9} \mathrm{Ir}_{0.1} \mathrm{O}_{3-\delta}$ is then evaluated by HRTEM. Moreover, since the performance of both $\mathrm{SrCo}_{0.9} \mathrm{Ir}_{0.1} \mathrm{O}_{3-\delta}$ and $\mathrm{m}-\mathrm{SrIrO}_{3}$ become stable in a few cycles (within 5 cycles), the surface structures of these two materials after 5 cycles were also investigated. The HRTEM images from pristine and cycled $\mathrm{m}-\mathrm{SrIrO}_{3}$ are presented in Fig. 2a. No apparent structural reconstruction can be observed from the surface of pristine $\mathrm{m}-\mathrm{SrIrO}_{3}$, while a surface reconstruction from cycled $\mathrm{m}-\mathrm{SrIrO}_{3}$ is observed with a depth of approximately $5 \mathrm{~nm}$. By comparing the FFT images from bulk 
a

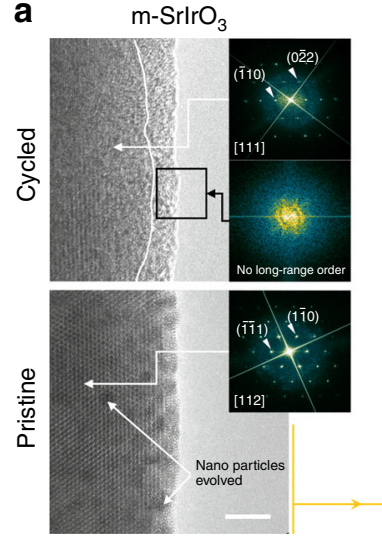

b
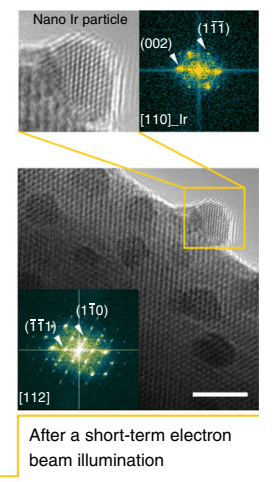

d

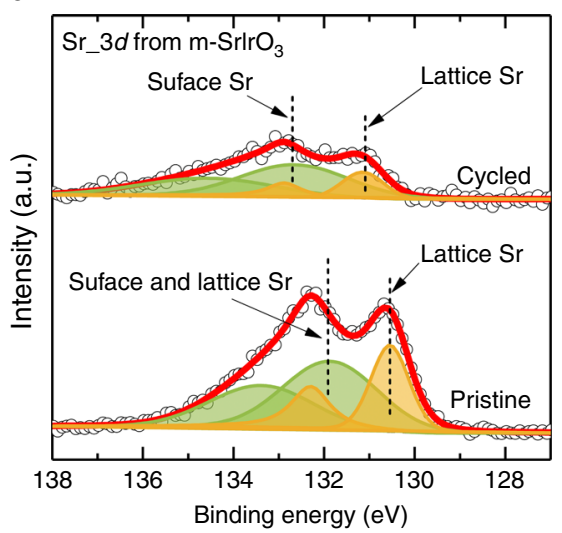

C $\quad \mathrm{SrCo}_{0.9} \mathrm{Ir}_{0.1} \mathrm{O}_{3-\delta}$

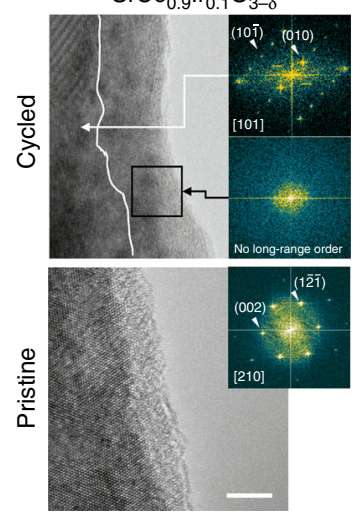

e

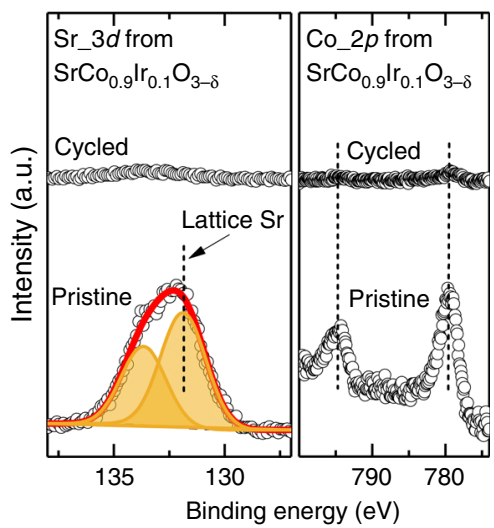

f

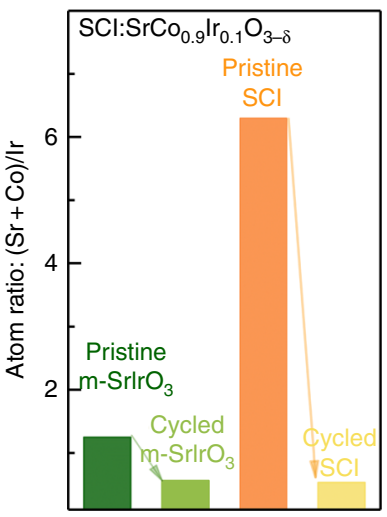

Fig. 2 Analysis of surface structure reconstruction. a High-resolution transmission electron microscopy (HRTEM) images of pristine and cycled m-SrlrO ${ }_{3}$ (by 5 cycles, scale bar, $5 \mathrm{~nm}$ ). b The HRTEM image of the exsolution of nanoparticles with increased size from m-Srlr $\mathrm{O}_{3}$ after a short-term electron beam illumination. The fast Fourier transformed (FFT) pattern from the nanoparticle can be indexed to a F $m \overline{3} m$ space group of Ir metal. The exsolution of nano Ir particles has no apparent effect on the crystallinity of surface region. c HRTEM images of pristine and cycled $\mathrm{SrCo}_{0.9} \mathrm{Ir}_{0.1} \mathrm{O}_{3-\delta}$ (by 5 cycles, scale bar, $5 \mathrm{~nm}$ ). The white curves in $\mathbf{a}$ and $\mathbf{c}$ indicate the interfaces between the crystallized region and the reconstructed region. The FFT patterns from the bulk of corresponding HRTEM images can be well indexed based on space groups of $\mathrm{C} 2 / \mathrm{c}$ for $\mathrm{m}-\mathrm{SrlrO}_{3}$ and $\mathrm{P} n m a$ for $\mathrm{SrCo}_{0.9} \mathrm{Ir}_{0.1} \mathrm{O}_{3-\delta}$. As reflected in the FFT patterns from the surfaces of cycled $\mathrm{m}-\mathrm{SrlrO}_{3}$ and cycled $\mathrm{SrCo}_{0.9} \mathrm{Ir}_{0.1} \mathrm{O}_{3-\delta}$, no long-range order exists in the surface regions. d $\mathrm{Sr}_{-} 3 d \mathrm{XPS}_{\mathrm{S}}$ for $\mathrm{m}-\mathrm{SrlrO} \mathrm{O}_{3}$ before and after 5 cyclic voltammetry (CV) cycles. e Sr_3d and $\mathrm{Co}_{-} 2 p$ XPS for $\mathrm{SrCo}_{0.9} \mid \mathrm{rr}_{0.1} \mathrm{O}_{3-\delta}$ before and after the electrochemical tests. $\mathbf{f}$ The surface $(\mathrm{Sr}+\mathrm{Co}):$ Ir ratio in $\mathrm{m}-\mathrm{SrlrO}_{3}$ and $\mathrm{SrCO}_{0.9} \mathrm{Ir}_{\mathrm{r}_{1.1} \mathrm{O}_{3-\delta}}$ before and after the electrochemical cycling

and surface, such reconstructed surface is likely amorphous with no long-range order. We caution that nanoparticles $(\sim 2 \mathrm{~nm})$ emerge from the bulk of the $\mathrm{m}-\mathrm{SrIrO}_{3}$ after a short-term electron beam illumination, and such nanoparticles were determined to be Ir (Fig. 2b). Similar behaviors have also been observed in a few other Ir-based oxides ${ }^{22,23}$. In spite of the formation of Ir nanoparticles, the crystallinity of the surfaces of $\mathrm{m}-\mathrm{SrIrO}_{3}$ was not affected during the period of TEM analysis. Figure $2 \mathrm{c}$ presents the HRTEM images from pristine and cycled $\mathrm{SrCo}_{0.9} \mathrm{Ir}_{0.1} \mathrm{O}_{3-\delta}$. The surface region from pristine $\mathrm{SrCo}_{0.9} \mathrm{Ir}_{0.1} \mathrm{O}_{3-\delta}$ with a depth of $1-3 \mathrm{~nm}$ is amorphous. Such slight surface amorphization in pristine $\mathrm{SrCo}_{0.9} \mathrm{Ir}_{0.1} \mathrm{O}_{3-\delta}$ likely occurs during the TEM sample preparation process, in which the sample is ultrasonically dispersed in ethanol solution. After electrochemical cycling, an apparent surface structure reconstruction is observed for $\mathrm{SrCo}_{0.9} \mathrm{Ir}_{0.1} \mathrm{O}_{3-\delta}$ with a depth of approximately $10 \mathrm{~nm}$. Similar to the case in $\mathrm{m}-\mathrm{SrIrO}_{3}$, such reconstructed surface of $\mathrm{SrCo}_{0.9} \mathrm{Ir}_{0.1} \mathrm{O}_{3-\delta}$ is also likely amorphous with no long range order. The FFT image from bulk of $\mathrm{SrCo}_{0.9} \mathrm{Ir}_{0.1} \mathrm{O}_{3-\delta}$ can be well indexed, indicating the bulk maintains its initial crystal structure. In combination with the observed reconstructed surface layers, the in situ reconstructed surface layers are responsible for the observed activities from the $\mathrm{m}-\mathrm{SrIrO}_{3}$ and the $\mathrm{SrCo}_{0.9} \mathrm{Ir}_{0.1} \mathrm{O}_{3-\delta}$.
The X-ray photoelectron spectroscopy (XPS) was then performed to study the surface chemical states in $\mathrm{m}-\mathrm{SrIrO}_{3}$ and $\mathrm{SrCo}_{0.9} \mathrm{Ir}_{0.1} \mathrm{O}_{3-\delta}$ before and after 5 cyclic voltammetry $(\mathrm{CV})$ cycles. The XPS of $\mathrm{Sr} \_3 d$ from the $\mathrm{m}-\mathrm{SrIrO}_{3}$ are shown in Fig. $2 \mathrm{~d}$. The fitting parameters are listed in Supplementary Table 2. To compare the relative composition change, all $\mathrm{Sr} \_3 d$ spectra are normalized based on corresponding Ir contents. In Fig. 2d, an apparent decrease in $\mathrm{Sr} \_3 d$ signal is observed from cycled $\mathrm{m}-\mathrm{SrIrO}_{3}$, indicating a $\mathrm{Sr}$ leaching during the test. Moreover, although the $\mathrm{Sr} \_3 d$ signal from pristine $\mathrm{m}-\mathrm{SrIrO}_{3}$ and cycled $\mathrm{m}-\mathrm{SrIrO}_{3}$ can both be fit with two doublets, their profile is totally different. Specifically, both doublets in the pristine $\mathrm{m}-\mathrm{SrIrO}_{3}$ should be mainly related to the $\mathrm{Sr}$ from $\mathrm{m}-\mathrm{SrIrO}_{3}$ lattice as two low binding energy of 130.55 and $131.81 \mathrm{eV}$ for the $3 d 5 / 2$ peak are obtained $^{24}$. In addition, a relative larger full width at half maximum (FWHM) for the second doublet (marked in green) indicates it also includes a small amount of surface $\mathrm{Sr}$ components, such as $\mathrm{SrO}, \mathrm{SrCO}_{3}$, and $\mathrm{Sr}(\mathrm{OH})_{2}$, with higher binding energies (above $133 \mathrm{eV})^{25}$. In the cycled $\mathrm{m}_{-} \mathrm{SrIrO}_{3}$, the first doublet (marked in yellow) with a low binding energy of $131.15 \mathrm{eV}$ should still be related to lattice Sr. More surface Sr components seem formed because the second doublet shifts to a higher binding energy of $132.62 \mathrm{eV}$ for the $3 d 5 / 2$ peak. In combination with the 
HRTEM results, the increased amount of surface Sr components is likely related to the leached bulk $\mathrm{Sr}$, which re-deposits on the electrode surface. Figure 2e shows the XPS of $\mathrm{Sr}_{-} 3 d$ and Co_2p from pristine and cycled $\mathrm{SrCo}_{0.9} \mathrm{Ir}_{0.1} \mathrm{O}_{3-\delta}$ samples. The fitting parameters for $\mathrm{Sr} \_3 d$ spectra are listed in Supplementary Table 3. In the spectrum of $\mathrm{Sr} \_3 d$ from pristine $\mathrm{SrCo}_{0.9} \mathrm{Ir}_{0.1} \mathrm{O}_{3-\delta}$ sample, only one doublet at $131.83 \mathrm{eV}$ for the $3 d 5 / 2$ peak is observed, which should be mainly related to lattice Sr. Importantly, a severe Sr leaching is observed from the cycled $\mathrm{SrCo}_{0.9} \mathrm{Ir}_{0.1} \mathrm{O}_{3-\delta}$ sample as the $\mathrm{Sr} \_3 d$ signal is almost invisible just after $5 \mathrm{CV}$ cycles (time of duration: $\sim 10 \mathrm{~min}$ ). Similarly, a fast cobalt leaching is observed from the surface of cycled $\mathrm{SrCo}_{0.9} \mathrm{Ir}_{0.1} \mathrm{O}_{3-\delta}$ because the XPS signal of Co_2 $p$ from cycled $\mathrm{SrCo}_{0.9} \mathrm{Ir}_{0.1} \mathrm{O}_{3-\delta}$ sample is almost invisible. As summarized in Fig. 2f, after 5 cycles, approximately $50 \% \mathrm{Sr}$ dissolved from the surface of $\mathrm{m}-\mathrm{SrIrO}_{3}$. In the reported PLD$\mathrm{SrIrO}_{3}$ catalyst, approximately $75 \% \mathrm{Sr}$ is expected to leach from its surface after $30 \mathrm{~min}$ of electrochemical OER testing ${ }^{13}$. Although the leaching degree of $\mathrm{Sr}$ from the surface of $\mathrm{m}-\mathrm{SrIrO}_{3}$ is slightly lower than that in $\mathrm{PLD}-\mathrm{SrIrO}_{3}$, considering the much inferior activity of $\mathrm{m}-\mathrm{SrIrO}_{3}$, the initial pseudo-cubic structure with corner-shared IrO6 octahedron is critical for a highly active Ir site after the cation leaching. This corresponds well with the previous calculation results ${ }^{13}$, which found the reconstructed surface with a structure similar to $\mathrm{IrO}_{3}$ or anatase $\mathrm{IrO}_{2}$ is active to catalyze OER. Different from $\mathrm{m}$ - and $\mathrm{PLD}_{-} \mathrm{SrIrO}_{3}$, the surface region of $\mathrm{SrCo}_{0.9} \mathrm{Ir}_{0.1} \mathrm{O}_{3-\delta}$ loses approximately $92 \% \mathrm{Sr}+\mathrm{Co}$ after $5 \mathrm{CV}$ cycles. This $\mathrm{Sr}$ and $\mathrm{Co}$ leaching in acid from $\mathrm{SrCo}_{0.9} \mathrm{Ir}_{0.1} \mathrm{O}_{3-\delta}$ likely causes the obvious surface reconstruction on $\mathrm{SrCo}_{0.9} \mathrm{Ir}_{0.1} \mathrm{O}_{3-\delta}$. More importantly, we can confirm the formed amorphous surface Ir-related species after $\mathrm{Sr}$ and Co leaching are responsible for the measured activity of $\mathrm{m}-\mathrm{SrIrO}_{3}$ and $\mathrm{SrCo}_{0.9} \mathrm{Ir}_{0.1} \mathrm{O}_{3-\delta}$.

Understanding Ir from reconstructed surfaces. Ir from $\mathrm{IrO}_{2}, \mathrm{~m}$ $\mathrm{SrIrO}_{3}$, and $\mathrm{SrCo}_{0.9} \mathrm{Ir}_{0.1} \mathrm{O}_{3-\delta}$ were investigated by XPS to gain more information about the Ir in reconstructed surfaces and the Ir_ $4 f$ spectra from the three samples before and after electrochemical tests are given in Fig. 3a. The $\mathrm{Ir}_{-} 4 f$ spectra from the $\mathrm{IrO}_{2}$ are studied first. Distinctive asymmetric tail can be observed from the peaks in the two spectra and is reported related to the screening response of $5 d$ conduction electrons ${ }^{26}$. Based on the previous studies, both $\operatorname{Ir} \_4 f$ spectra can be fitted with two doublets and an additional single satellite peak. The fitting results are listed in Supplementary Table 4 . The Ir_4f7/2 peak with a binding energy of 61.61 and $61.63 \mathrm{eV}$ is found from the first doublet (marked in yellow) in the pristine $\mathrm{IrO}_{2}$ and the cycled $\mathrm{IrO}_{2}$, respectively. The observed binding energies are within the reported ranges for $\mathrm{Ir}_{4} 4 f 7 / 2$ peak in $\mathrm{IrO}_{2}(61-62 \mathrm{eV})$. The second wide doublet (marked in green), with an energy shift of approximately $1 \mathrm{eV}$ as compared with the first doublet, should be related to the shake-up satellites of the first doublet ${ }^{27}$. The spin-orbit splitting in both doublets is $2.98-2.99 \mathrm{eV}$, which is also close to the reported values ${ }^{27-29}$. The additional single satellite at $67.6 \mathrm{eV}$ for pristine $\mathrm{IrO}_{2}$ or at $67.76 \mathrm{eV}$ for the cycled $\mathrm{IrO}_{2}$ is related to the localized non-bonding states ${ }^{27,28}$. From the fitting results, the Ir $4 f$ spectra from the $\mathrm{IrO}_{2}$ is almost unchanged after the electrochemical cycling, confirming a highly stable surface structure of $\mathrm{IrO}_{2}$ during OER in acidic environment.

The Ir_ $4 f$ spectra from the $\mathrm{m}-\mathrm{SrIrO}_{3}$ were also fit to explore the change of surface Ir after electrochemical cycling. The fitting parameters are listed in Supplementary Table 2. Both spectra can be fit with two doublets. In the pristine $\mathrm{m}-\mathrm{SrIrO}_{3}$, the $\mathrm{Ir} \_4 f 7 / 2$ peak from the first doublet located at a low binding energy of $60.33 \mathrm{eV}$, which is generally considered as the signal of Ir metal ${ }^{30}$. However, Ir metal is unlikely to exist in the sample as a long-term high temperature calcination is required in the solid state method for sample preparation. Considering the Ir in the $\mathrm{m}-\mathrm{SrIrO}_{3}$ is $4+$ for charge neutrality, it is rational to define this first doublet comes from $\mathrm{Ir}^{4+}$. Moreover, in the previous studies, the $\mathrm{Ir} \_4 f 7 / 2$ peak of $\mathrm{Ir}^{4+}$ from $\mathrm{PLD}_{-} \mathrm{SrIrO}_{3}$ is found with a binding energy located in between 61.8 and $62.6 \mathrm{eV}^{13}$. The much lower binding energy observed in the $\mathrm{m}-\mathrm{SrIrO}_{3}$ indicates the XPS signal of $\mathrm{Ir}$ is strongly related to its local structural environment. The second doublet has a binding energy $\sim 1.4 \mathrm{eV}$ higher than that of the first doublet. This energy shift between two doublets is similar to the cases observed in rutile $\mathrm{IrO}_{2}$ and $\mathrm{PLD}-\mathrm{SrIrO}_{3}$, indicating the second doublet should be shake-up satellites. After electrochemical cycling, apparent shifts of the two doublets in the Ir_4f spectra to higher binding energy are observed. The Ir_4f7/2 in the first doublet is at $61.2 \mathrm{eV}$, which is approximately $0.9 \mathrm{eV}$ higher than that in pristine $\mathrm{m}-\mathrm{SrIrO}_{3}$. This moderate energy shift is different from the case observed in $\mathrm{PLD}_{-} \mathrm{SrIrO}_{3}$, in which the Ir_ $4 f 7 / 2$ in the first doublet is almost unchanged irrespective of the Sr leaching during electrochemical testing ${ }^{13}$. The Sr leaching in $\mathrm{m}-\mathrm{SrIrO}_{3}$ probably influences the chemical state of $\mathrm{Ir}$ and thus certain $\mathrm{Sr}_{x} \mathrm{IrO}_{y} \mathrm{H}_{z}(x<1)$ phase(s) may form, considering a high amount of Sr remains in the surface. The Ir_ $4 f 7 / 2$ peak from the second doublet has a high binding energy of $63.35 \mathrm{eV}$, which, however, cannot be solely treated as the shake-up satellites because an energy shift of approximately $2.2 \mathrm{eV}$, relative to the first doublet, is observed. Such energy shift is much larger than those $(1-1.6 \mathrm{eV})$ observed in rutile $\mathrm{IrO}_{2}, \mathrm{PLD}-\mathrm{SrIrO}_{3}$ as well as the pristine $\mathrm{m}-\mathrm{SrIrO}_{3}$. The unusual energy shift of this second doublet hints the formed surface is very complex and multiple phases can exist.

The profile of Ir_ $4 f$ spectra from the pristine $\mathrm{SrCo}_{0.9} \mathrm{Ir}_{0.1} \mathrm{O}_{3-\delta}$ is different from those observed in rutile $\mathrm{IrO}_{2}$ or $\mathrm{SrIrO}_{3}$ phases. The fitting parameters are listed in Supplementary Table 3. The fitting results revealed an Ir_ $4 f 7 / 2$ peak at approximately $59.7 \mathrm{eV}$ for the first doublet. This Ir_ $4 f 7 / 2$ peak with a large FWHM likely represents the mixed $\mathrm{Ir}^{4 / 5+}$ in $\mathrm{SrCo}_{0.9} \mathrm{Ir}_{0.1} \mathrm{O}_{3-\delta}$ since a low binding energy is also observed in the pristine $\mathrm{m}-\mathrm{SrIrO}_{3}$ phase. The second doublet with a binding energy $\sim 2 \mathrm{eV}$ higher than the first doublet cannot be solely treated as the shake-up satellite. Certain Ir specie(s) from $\mathrm{SrCo}_{0.9} \mathrm{Ir}_{0.1} \mathrm{O}_{3-\delta}$ surface can exist, and its identification is beyond the scope of this study. After electrochemical cycling, the $\mathrm{Ir}$ - $4 f$ spectra from $\mathrm{SrCo}_{0.9} \mathrm{Ir}_{0.1} \mathrm{O}_{3-\delta}$ can be well fit with two doublets. A binding energy of $61.0 \mathrm{eV}$ is observed for the Ir_4f7/2 peak in the first doublet. Such peak position is more than $1 \mathrm{eV}$ higher than that in pristine $\mathrm{SrCo}_{0.9} \mathrm{Ir}_{0.1} \mathrm{O}_{3-\delta}$, but $\sim 0.6 \mathrm{eV}$ lower than that in rutile $\mathrm{IrO}_{2}$. The second doublet in cycled $\mathrm{SrCo}_{0.9} \mathrm{Ir}_{0.1} \mathrm{O}_{3-\delta}$ shifts $\sim 1.5 \mathrm{eV}$ to higher binding energy, which then can be related to the shake-up satellites. As a result, certain $\mathrm{IrO}_{x} \mathrm{H}_{y}$ phase may form over the $\mathrm{SrCo}_{0.9} \mathrm{Ir}_{0.1} \mathrm{O}_{3-\delta}$ surface as $\mathrm{Sr}$ and $\mathrm{Co}$ have leached out. Previously, some amorphous $\mathrm{IrO}_{x}$ phases have also been prepared for a higher activity than crystallized rutile $\mathrm{IrO}_{2} 22,31,32$. However, the $\mathrm{Ir}_{-} 4 f$ spectra from amorphous $\mathrm{IrO}_{x}$ and crystalline rutile $\mathrm{IrO}_{2}$ always have similar peak positions and profiles ${ }^{27,31-33}$. Moreover, the influence of Sr on Ir_ $4 f$ in XPS can be excluded since there is almost no $\mathrm{Sr}$ in the surface region after five cycles (Fig. 2e). In fact, the signals of $\mathrm{Sr}$ and $\mathrm{Co}$ in XPS from the surface region of $\mathrm{SrCo}_{0.9} \mathrm{Ir}_{0.1} \mathrm{O}_{3-\delta}$ disappeared completely after 10k cycles (Supplementary Figure $3 \mathrm{a} \& \mathrm{~b}$ ). That indicates only Ir remaining in the surface region. Therefore, the possibility that the residual $\mathrm{Sr}$ caused the difference (Fig. 3a and Supplementary Figure 3c) in Ir_4 $f$ between cycled $\mathrm{SrCo}_{0.9} \mathrm{Ir}_{0.1} \mathrm{O}_{3-\delta}$ and hydrous $\mathrm{IrO}_{x}$ can be excluded. As a result, the formed $\mathrm{IrO}_{x} \mathrm{H}_{y}$ phase in $\mathrm{SrCo}_{0.9} \mathrm{Ir}_{0.1} \mathrm{O}_{3-\delta}$ is different from previous amorphous $\mathrm{IrO}_{x}$ phases.

For a better understanding of the formation and evolution of the surface in $\mathrm{m}-\mathrm{SrIrO}_{3}$ and $\mathrm{SrCo}_{0.9} \mathrm{Ir}_{0.1} \mathrm{O}_{3-\delta}$, we further studied the CV cycles measured from $\mathrm{SrCo}_{0.9} \mathrm{Ir}_{0.1} \mathrm{O}_{3-\delta}$ and $\mathrm{m}-\mathrm{SrIrO}_{3}$. 

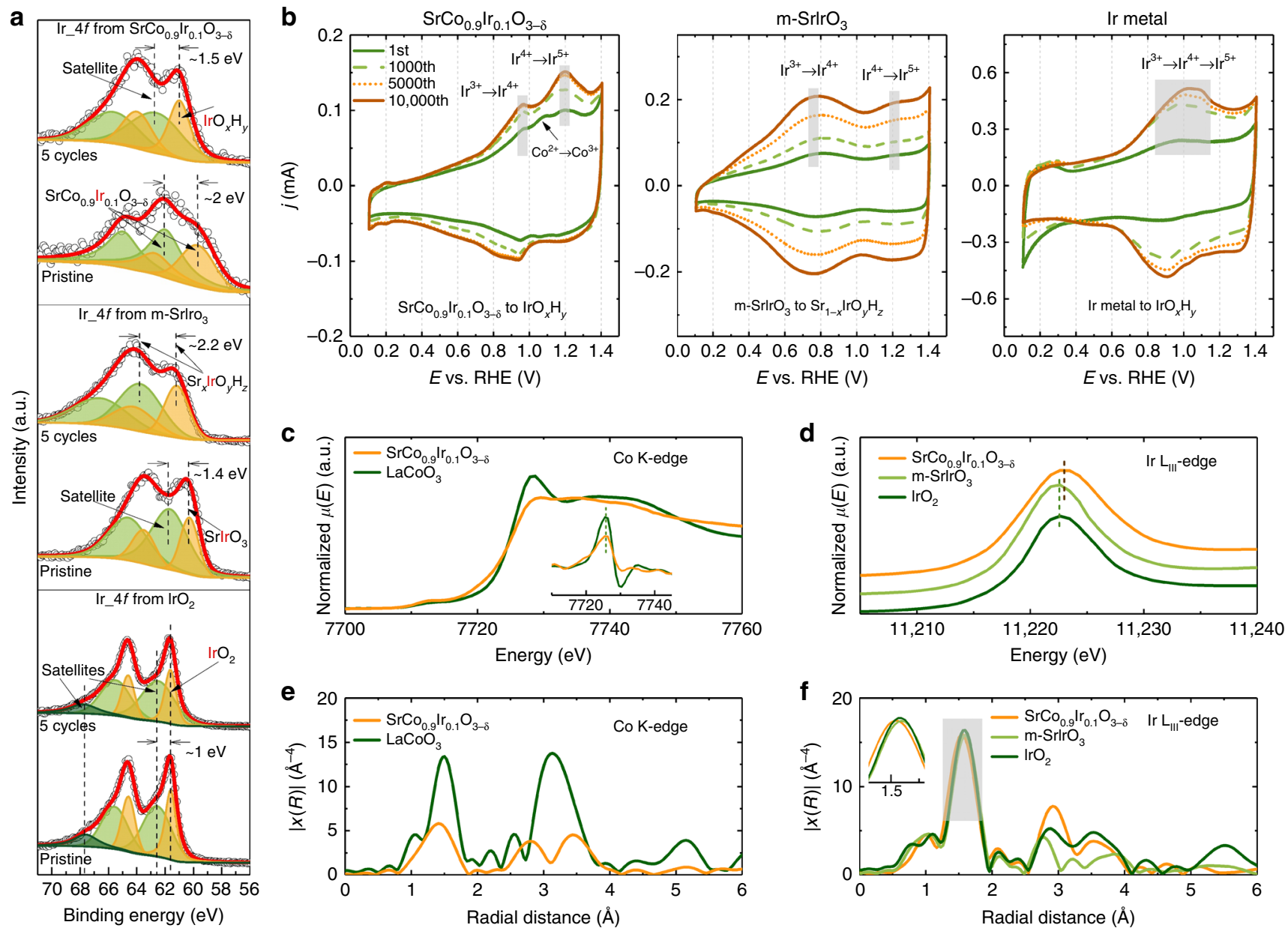

Fig. 3 Evaluation of the formed $\mathrm{IrO}_{x}$ phase(s) and $\mathrm{SrCO}_{0.9} \mathrm{Ir}_{0.1} \mathrm{O}_{3-\delta}$ bulk chemical states. a Ir_4f X-ray photoelectron spectroscopy (XPS) for IrO ${ }_{2}, \mathrm{~m}_{-} \mathrm{Sr}$ IrO $\mathrm{O}_{3}$, and $\mathrm{SrCO}_{0.9} \mathrm{Ir}_{0.1} \mathrm{O}_{3-\delta}$ before and after the electrochemical tests. b The cyclic voltammetry (CV) curves recorded at the 1st, 1000th, 5000th, and 10,000th cycles for $\mathrm{SrCO}_{0.9} \mid \mathrm{rr}_{0.1} \mathrm{O}_{3-\delta}, \mathrm{m}_{-} \mathrm{SrlrO}_{3}$, and Ir metal in a $0.1 \mathrm{M} \mathrm{HClO}_{4}$ electrolyte. The cycles presented are collected at a scan rate of $100 \mathrm{mV} \mathrm{s}{ }^{-1}$. For the intermediate cycles, a scan rate of $1 \mathrm{~V} \mathrm{~s}^{-1}$ is applied. $\mathbf{c}$ X-ray absorption near edge structure (XANES) and 1st derivative XANES spectra (inset) of LaCoO ${ }_{3}$

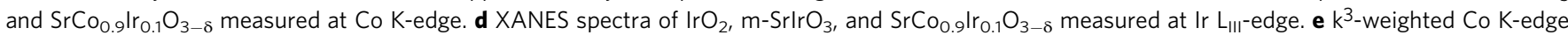
Extended X-Ray Absorption Fine Structure (EXAFS) spectra of $\mathrm{LaCoO}_{3}$ and $\mathrm{SrCo}_{0.9} \mathrm{Ir}_{0.1} \mathrm{O}_{3-\delta}$. $\mathbf{f} \mathrm{k}^{3}$-weighted Ir $\mathrm{L}_{\| 1}$-edge EXAFS spectra of IrO $\mathrm{E}_{2}$, m-SrlrO${ }_{3}$, and $\mathrm{SrCo}_{0.9} \mathrm{Ir}_{0.1} \mathrm{O}_{3-\delta}$

Since Ir hydrous oxide can be formed on metal Ir through electrochemical cycling, the CVs of Ir metal was also recorded for comparison $^{34}$. As shown in Fig. 3b, different redox behaviors are observed for Ir from these three catalysts. For $\mathrm{SrCo}_{0.9} \mathrm{Ir}_{0.1} \mathrm{O}_{3-\delta}$, three oxidation peaks, representing $\mathrm{Ir}^{3+/ 4+}(\sim 1 \mathrm{~V}), \mathrm{Co}^{2+/ 3+}$ $(\sim 1 \mathrm{~V})$, and $\operatorname{Ir}^{4+/ 5+}(\sim 1.2 \mathrm{~V})$, can be observed at the first cycle $^{35,36}$. In the following cycles, the Co peak disappeared and only the two peaks belonging to Ir become remarkable, which is probably due to the dissolution of $\mathrm{Co}$ as well as the formation of $\mathrm{IrO}_{x} \mathrm{H}_{y}$ species in the surface region. The intensities of the two Irrelated oxidation peaks simultaneously increased, which should be related to the increased degree of surface reconstruction. Interestingly, the surface reconstruction process likely stopped after 5000 cycles since the 5,000th cycle almost overlapped with the 10,000 th cycle. The peak at $\sim 1.2 \mathrm{~V}$ indicates the oxidation of $\mathrm{Ir}^{4+}$ to $\mathrm{Ir}^{5+}$ is greatly facilitated over the $\mathrm{SrCo}_{0.9} \mathrm{Ir}_{0.1} \mathrm{O}_{3-\delta}$ surface. For $\mathrm{m}-\mathrm{SrIrO}_{3}$, two oxidation peaks, representing $\mathrm{Ir}^{3+/ 4+}(\sim 0.8 \mathrm{~V})$ and $\operatorname{Ir}^{4+/ 5+}(\sim 1.2 \mathrm{~V})$, can be observed. However, unlike $\mathrm{SrCo}_{0.9} \mathrm{Ir}_{0.1} \mathrm{O}_{3-\delta}$, the redox of $\mathrm{Ir}^{3+} / \mathrm{Ir}^{4+}$ is dominant on $\mathrm{m}$ $\mathrm{SrIrO}_{3}$. As for Ir metal, one distinctive oxidation peak at $\sim 1 \mathrm{~V}$ is observed after $\sim 1000$ cycles, indicating the formation of surface Ir hydrous oxide. Such broad oxidation peak likely due to successive oxidation of $\mathrm{Ir}^{3+}$ to $\mathrm{Ir}^{5+35}$. By comparing the CVs of these three catalysts, one can conclude that they give different Ir-based amorphous phase(s) by cycling. The formation of different Irrelated phase(s) over these catalysts is also indicated by corresponding XPS results (Supplementary Figure 3 and Supplementary Table 5). More importantly, the profiles of CVs (the 5000th/10,000th cycle) from cycled samples resemble those of 1st cycle, strongly suggest that the formed Ir-based amorphous phase(s) are strongly influenced by the initial lattice.

Possible active phase after surface reconstruction. Till now, several facts have been put forward to explain the high activities measured from Ir-based complex oxides with perovskite or perovskite-related structures ${ }^{12-15}$. For example, derived from $\mathrm{Sr}$ leached $\mathrm{SrIrO}_{3}$, it is revealed certain $\mathrm{IrO}_{x}$, with structure resemble cubic perovskite, is highly active towards $\mathrm{OER}^{13}$. A similar conclusion was obtained from Ir-based double perovskites, that is Ir is more active in $3 \mathrm{D}$ network of corner-shared octahedrons ${ }^{12}$. Although the surfaces of these double perovskites may also experience fast surface rearrangement, the initial cubic perovskite structure with corner-shared octahedrons seems to be a key factor that influence or even determine the activity of formed surface active phase(s). This may also explain the inferior activity of $\mathrm{m}$ $\mathrm{SrIrO}_{3}$ in our study. In fact, for an amorphous $\mathrm{IrO}_{x}$, the strong 
correlation between activity and local structure (corner-shared vs. edge-shared IrO6 octahedrons) has also been highlighted by Willinger et al. ${ }^{23}$. Besides, it is reported that certain lattice oxygen atom can be activated in a $\mathrm{La}_{2} \mathrm{LiIrO}_{6}$ perovskite. Such activated lattice oxygen atom can participate in the OER and is proposed critical for the observed high activity ${ }^{15}$. However, as surface reconstruction is observed in our catalysts, the activated lattice oxygen atom from perovskite is unlikely. We hypothesized that the high activity of $\mathrm{IrO}_{x} \mathrm{H}_{y}$ evolved from $\mathrm{SrCo}_{0.9} \mathrm{Ir}_{0.1} \mathrm{O}_{3-\delta}$ due to the strong correlation between the $\operatorname{IrO}_{x} \mathrm{H}_{y}$ and the initial/bulk lattice of $\mathrm{SrCo}_{0.9} \mathrm{Ir}_{0.1} \mathrm{O}_{3-\delta}$.

In the developed $\mathrm{SrCo}_{0.9} \mathrm{Ir}_{0.1} \mathrm{O}_{3-\delta}$, first of all, its pseudo-cubic structure with initially corner-shared octahedrons can induce the formation of a local structure optimized $\operatorname{IrO}_{x} \mathrm{H}_{y}$ phase, which still contains a high ratio of corner-shared IrO6 octahedrons. However, this is insufficient to explain the measured higher activity when compared with that from the reported PLD-SrIrO ${ }_{3}^{13}$. As compared with $\mathrm{SrIrO}_{3}$ and other reported Ir-based perovskites, the $\mathrm{SrCo}_{0.9} \mathrm{Ir}_{0.1} \mathrm{O}_{3-\delta}$ here is expected to possess a high amount of oxygen vacancies in the lattice since the $\mathrm{SrCoO}_{3-\delta}$ matrix is highly oxygen deficient ${ }^{37}$. Accordingly, the oxygen vacancy formation energies for $\mathrm{m}$-SrIrO $\mathrm{S}_{3}, \mathrm{PLD}-\mathrm{SrIrO}_{3}$, and $\mathrm{SrCo}_{0.9} \mathrm{Ir}_{0.1} \mathrm{O}_{3}$ were calculated by density functional theory (DFT). Moreover, the $\mathrm{O}$ $p$-band centers of different materials were also calculated. This is because a perovskite with an $\mathrm{O} p$-band center close to Fermi level was found easier to release oxygen, i.e., the formation of oxygen vacancies $^{38}$ (computation details and discussions are shown in Supplementary Figure 4\&5 and Supplementary Table 6). As compared with $\mathrm{m}$-SrIrO $\mathrm{H}_{3}$ and $\mathrm{PLD}-\mathrm{SrIrO}_{3}$, the DFT calculations indicate that the $\mathrm{SrCo}_{0.9} \mathrm{Ir}_{0.1} \mathrm{O}_{3-\delta}$ could contain a higher amount of oxygen vacancies.

To further investigate the oxygen vacancies in $\mathrm{SrCo}_{0.9} \mathrm{Ir}_{0.1} \mathrm{O}_{3-\delta}$, the X-ray adsorption spectroscopy (XAS) was performed to check the valence state and coordination environment of Co and Ir. As shown in Fig. 3c, the average valence state of $\mathrm{Co}$ in the $\mathrm{SrCo}_{0.9} \mathrm{Ir}_{0.1} \mathrm{O}_{3-\delta}$ is approximately $3+$ by comparing with the Co $\mathrm{K}$-edge from the standard $\mathrm{LaCoO}_{3}$, in which the Co is strictly trivalent state ${ }^{39,40}$. Considering the Ir- $\mathrm{L}_{\text {III }}$ edge positions from m$\mathrm{SrIrO}_{3}$ and $\mathrm{IrO}_{2}$ are similar to each other (Fig. 3d), the oxidation state of $\mathrm{Ir}$ in $\mathrm{m}-\mathrm{SrIrO}_{3}$ is approximately $4+$, indicating almost no oxygen vacancy in $\mathrm{m}-\mathrm{SrIrO}_{3}$. The valence state of $\mathrm{Ir}$ in $\mathrm{SrCo}_{0.9} \mathrm{Ir}_{0.1} \mathrm{O}_{3-\delta}$ is found slightly higher than $4+$ as the Ir- $\mathrm{L}_{\text {III }}$ edge shifts to higher energy as compared with $\mathrm{IrO}_{2}$. For charge neutrality, the $\delta$ (oxygen nonstoichiometry) in $\mathrm{SrCo}_{0.9} \mathrm{Ir}_{0.1} \mathrm{O}_{3-\delta}$ can reach a minimum value of 0.4 if assuming all Ir is pentavalent state. Therefore, a high amount of oxygen vacancies should exist in $\mathrm{SrCo}_{0.9} \mathrm{Ir}_{0.1} \mathrm{O}_{3}$, and thus both Co and $\mathrm{Ir}$ in $\mathrm{SrCo}_{0.9} \mathrm{Ir}_{0.1} \mathrm{O}_{3-\delta}$ are highly under-coordinated. Accordingly, the Fourier transformed (FT) EXAFS spectra in R-space for Co and Ir in $\mathrm{SrCo}_{0.9} \mathrm{Ir}_{0.1} \mathrm{O}_{3-\delta}$ are compared with the spectra from standard $\mathrm{LaCoO}_{3}, \mathrm{~m}-\mathrm{SrIrO}_{3}$, and $\mathrm{IrO}_{2}$, in which Co and Ir are fully or almost fully coordinated. In FT EXAFS spectra, the peaks are related to the coordination shells of Ir and Co. Specifically, the first peak represents the first Ir/ $\mathrm{Co}-\mathrm{O}$ shell caused by the interference between the electronic back scatterings from $\mathrm{Ir} / \mathrm{Co}$ to neighbor $\mathrm{O}$. Figure $3 \mathrm{e}$ shows the FT EXAFS spectra of the Co K edge from $\mathrm{SrCo}_{0.9} \mathrm{Ir}_{0.1} \mathrm{O}_{3-\delta}$. The first peak at a reduced distance of $\sim 1.5 \AA$ represents the first Co-O coordination shell in $\mathrm{SrCo}_{0.9} \mathrm{Ir}_{0.1} \mathrm{O}_{3-\delta}$ and it shows a much lower intensity as compared with the first peak from $\mathrm{LaCoO}_{3}$, indicating the highly under-coordinated Co. Additional evidence of such high oxygen-deficiency is obtained from the fitting of the first peaks, where the coordination number of $\mathrm{Co}$ in $\mathrm{SrCo}_{0.9} \mathrm{Ir}_{0.1} \mathrm{O}_{3-\delta}$ is approximately 4.1 (Supplementary Figure 6 and Supplementary Table 7). The comparison of FT EXAFS spectra at the Ir $\mathrm{L}_{\mathrm{III}}$-edge from $\mathrm{IrO}_{2}, \mathrm{~m}-\mathrm{SrIrO}_{3}$, and $\mathrm{SrCo}_{0.9} \mathrm{Ir}_{0.1} \mathrm{O}_{3-\delta}$ is shown in Fig. 3f. The first peak (at $\sim 1.5 \AA$ ) from $\mathrm{IrO}_{2}$ and $\mathrm{m}-\mathrm{SrIrO}_{3}$ overlaps to each other, while a shift to lower distance (shown in the inset of Fig. 3f) is found for $\mathrm{SrCo}_{0.9} \mathrm{Ir}_{0.1} \mathrm{O}_{3-\delta}$, implying a shorter average Ir-O bond length in $\mathrm{SrCo}_{0.9} \mathrm{Ir}_{0.1} \mathrm{O}_{3-\delta}$. The fitting of first Ir-O coordination shells also confirms this reduced bond length. (Supplementary Figure 7 and Supplementary Table 8). As expected, a first shell fitting indicates $\mathrm{Ir}$ in $\mathrm{SrCo}_{0.9} \mathrm{Ir}_{0.1} \mathrm{O}_{3-\delta}$ is also highly under-coordinated with a coordination number of $\sim 4.9$. Instead, the $\mathrm{Ir}$ in $\mathrm{m}-\mathrm{SrIrO}_{3}$ is fully coordinated, which is consistent with the DFT result.

Based on the results shown in Figs. 2 and 3, a schematic in Fig. 4 is proposed to illustrate the possible surface reconstruction over the $\mathrm{SrCo}_{0.9} \mathrm{Ir}_{0.1} \mathrm{O}_{3-\delta}$ surface. In initial $\mathrm{SrCo}_{0.9} \mathrm{Ir}_{0.1} \mathrm{O}_{3-\delta}$, the IrO6 octahedrons are corner-shared with surrounding (Co/Ir)O6 octahedrons. Due to the presence of oxygen vacancies, the Ir in the lattice is under-coordinated. During electrochemical cycling, fast leaching of $\mathrm{Sr}$ and Co leaves an Ir rich surface. The initial pseudo-cubic structure will collapse on the surface and the formed $\mathrm{IrO}_{x} \mathrm{H}_{y}$ phase(s) is amorphous without long-range ordering. The formed $\mathrm{IrO}_{x} \mathrm{H}_{y}$ phase(s) may contain a high amount of structural domains with corner-shared IrO6 octahedrons. Moreover, the Ir in the amorphous phase could be more under-coordinated as compared with those derived from $\mathrm{SrIrO}_{3}$ after Sr leaching. This deduction also explains why the activity of Ir from $\mathrm{SrCo}_{0.9} \mathrm{Ir}_{0.1} \mathrm{O}_{3-\delta}$ is higher than that of Ir from electrochemically cycled $\mathrm{SrIrO}_{3}$.

Assessing the stability of $\mathrm{SrCo}_{0.9} \mathrm{Ir}_{\mathbf{0 . 1}} \mathrm{O}_{3-\delta}$. Most recently, Geiger et al. proposed a stability number (S-number), considering the dissolution of active sites, is a proper metric to evaluate the stability of catalysts ${ }^{41}$. Thus, in this study, we also calculate the $\mathrm{S}$-number of $\mathrm{Ir}$ in $\mathrm{SrCo}_{0.9} \mathrm{Ir}_{0.1} \mathrm{O}_{3-\delta}$. The dissolution of cations, including $\mathrm{Sr}, \mathrm{Co}$, and $\mathrm{Ir}$, from $\mathrm{SrCo}_{0.9} \mathrm{Ir}_{0.1} \mathrm{O}_{3-\delta}$ during electrochemical tests are studied. The amount of dissolved cations during the cycling are shown in Fig. 5a. The corresponding overall dissolved Sr, Co, and Ir from $\mathrm{SrCo}_{0.9} \mathrm{Ir}_{0.1} \mathrm{O}_{3-\delta}$ during the cycling are shown in Supplementary Figure 8. The dissolution of Ir from Ir metal is also measured for comparison. At the early stage (0-100 cycles), fast $\mathrm{Sr}, \mathrm{Co}$, and $\mathrm{Ir}$ dissolution is observed from $\mathrm{SrCo}_{0.9} \mathrm{Ir}_{0.1} \mathrm{O}_{3-\delta}$. The simultaneous dissolution of $\mathrm{Sr}$ and $\mathrm{Co}$ likely induces such high dissolution rate of Ir. In the following cycles, the dissolution rate of Ir from $\mathrm{SrCo}_{0.9} \mathrm{Ir}_{0.1} \mathrm{O}_{3-\delta}$ is found slowed down. Interestingly, the apparently reduced dissolution rates of $\mathrm{Sr}$ and Co suggests that the dissolution of $\mathrm{Sr}$ and $\mathrm{Co}$ from $\mathrm{SrCo}_{0.9} \mathrm{Ir}_{0.1} \mathrm{O}_{3-\delta}$ is kinetically hindered by the formed Ir-rich surface layer. Similarly, The Ir metal also showed a gradually decreased rate of Ir dissolution. That is the formation of active Ir hydrous oxide also causes a fast Ir dissolution at the early stage. Figure $5 \mathrm{~b}$ shows the potential profiles of as-synthesized/purchased $\mathrm{SrCo}_{0.9} \mathrm{Ir}_{0.1} \mathrm{O}_{3-\delta}$, Ir metal, and $\mathrm{IrO}_{2}$ by chronopotentiometry method. Regardless of potential fluctuations caused by intermittent $\mathrm{O}_{2}$ bubbles released from the electrode surface, fairly stable performance is observed for all samples. The stability for different catalysts is then compared using their S-numbers, which are calculated by dividing the amount of oxygen molecules evolved by the amount of Ir dissolved in the electrolyte ${ }^{41}$. Moreover, as the surface reconstruction with fast cation dissolution (Fig. 5a) may greatly affect the following S-number calculation, both $\mathrm{SrCo}_{0.9} \mathrm{Ir}_{0.1} \mathrm{O}_{3-\delta}$ and Ir metal electrodes are pre-treated at $10 \mathrm{~mA} \mathrm{~cm}{ }^{-2}$ for $60 \mathrm{~min}$ (Supplementary Figure 9) for reaching the steady state. Figure $5 c$ shows S-numbers for $\mathrm{SrCo}_{0.9} \mathrm{Ir}_{0.1} \mathrm{O}_{3-\delta}$, Ir metal, and $\mathrm{IrO}_{2}$. Here, all $\mathrm{S}$-numbers are calculated according to the amount of dissolved Ir measured during chronopotentiometry (Fig. 5b and Supplementary Figure 9). The S-numbers of different oxides reported by Geiger et al. are also presented ${ }^{41}$. Due to the initial surface 


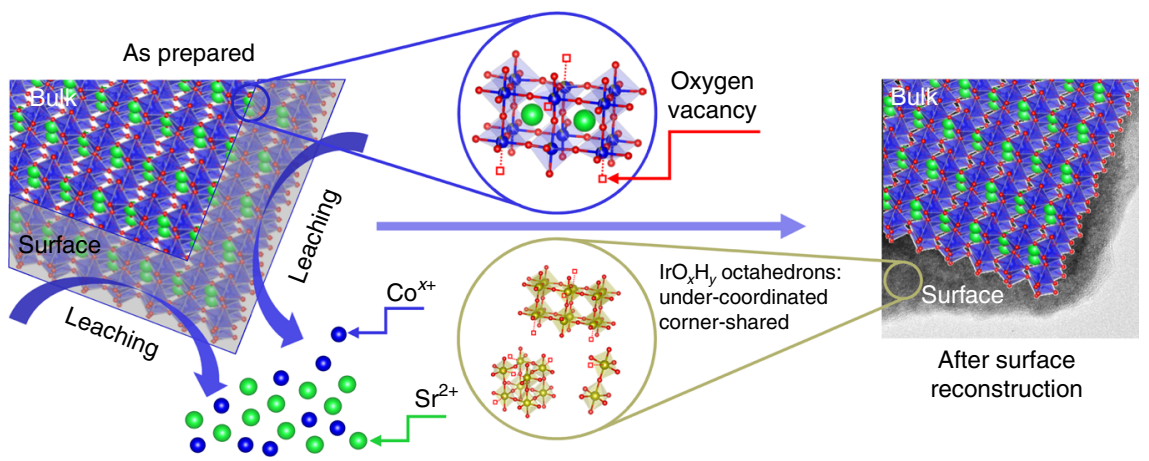

Fig. 4 Surface reconstruction. A schematic that illustrates the surface reconstruction over the $\mathrm{SrCo}_{0.9} \mathrm{Ir}_{0.1} \mathrm{O}_{3-\delta}$ surface
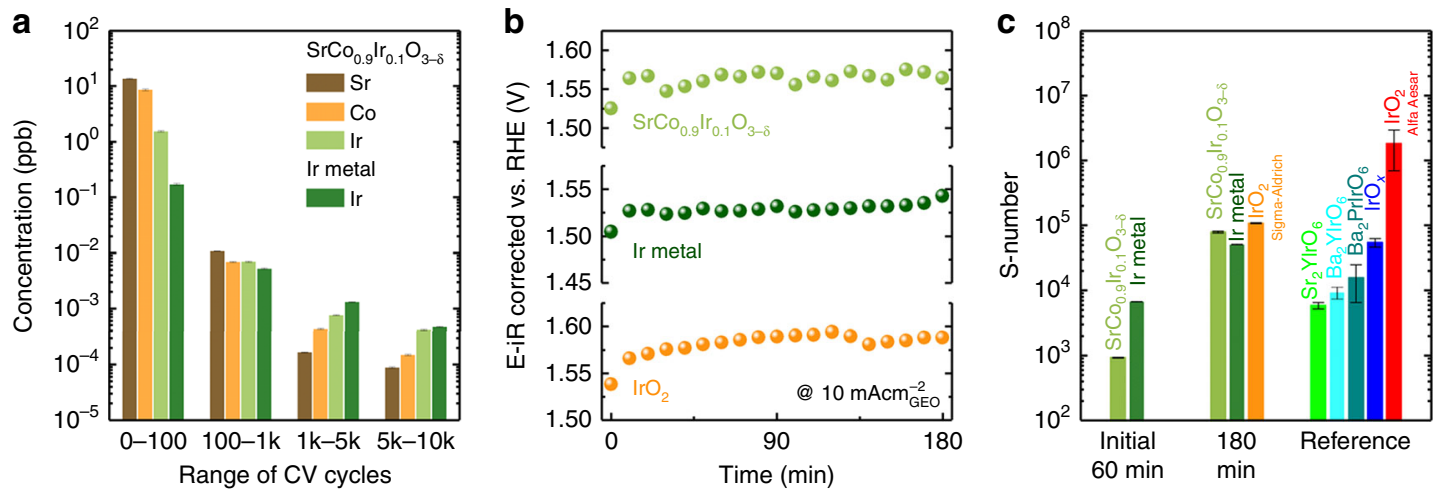

Fig. 5 Stability of $\mathrm{SrCo}_{0.9} \mathrm{Ir}_{0.1} \mathrm{O}_{3-\delta}$. a The averaged concentration of dissolved cations per cycle at different stages. The scan rate is $1 \mathrm{~V} \mathrm{~s}^{-1}$. For the $\mathrm{SrCo}_{0.9} \mathrm{Ir}_{0.1} \mathrm{O}_{3-\delta}$ electrode, the potential range is $0.1-1.4 \mathrm{~V}$ (vs. $\mathrm{RHE}$ ). As to the Ir metal electrode, to improve the Ir dissolution, the potential range for the initial $1 \mathrm{k}$ cycles and the rest $9 \mathrm{k}$ cycles is $0.1-1.6 \mathrm{~V}$ (vs. RHE) and 0.1-1.8 V (vs. RHE), respectively. Moreover, a higher overpotential (1.8 V vs. 1.6 V) applied in the rest $9 \mathrm{k}$ cycles for $\mathrm{Ir}$ metal can facilitate the Ir dissolution ${ }^{41}$. However, we can see that after $1 \mathrm{k}$ cycles, even the upper limit is increased to $1.8 \mathrm{~V}$ for $\mathrm{Ir}$ metal, there is no significant increase of Ir dissolution within the following $9 \mathrm{k}$ cycles. Instead, a lower Ir dissolution is observed, indicating a high instability of Ir at the early stage. $\mathbf{b}$ Potential profiles of different electrodes. The chronopotentiometry is performed in $0.1 \mathrm{M} \mathrm{HClO}_{4}$ at $10 \mathrm{~mA} \mathrm{~cm}{ }^{-2}$, which is normalized to the geometric area of electrodes (GEO). Please note that it does not reflect the intrinsic activity of these materials. c The calculated $\mathrm{S}$-numbers of $\mathrm{SrCo}_{0.9} \mathrm{Ir}_{0.1} \mathrm{O}_{3-\delta}$ I Ir metal, and $\mathrm{IrO}_{2}$. The S-numbers of some Ir-based perovskites reported by Geiger et al. are also presented 41

reconstruction, much lower S-numbers $\left(10^{3}-10^{4}\right)$ are observed from $\mathrm{SrCo}_{0.9} \mathrm{Ir}_{0.1} \mathrm{O}_{3-\delta}$ and Ir metal during the pre-treatment stage (initial $60 \mathrm{~min}$ ). Interestingly, from the following $180 \mathrm{~min}$ test, the S-number of $\mathrm{SrCo}_{0.9} \mathrm{Ir}_{0.1} \mathrm{O}_{3-\delta}$ steeply increased to approximately $10^{5}$, which is approximately one order of magnitude higher than the S-numbers of reported perovskites. In addition, the S-numbers of $\mathrm{SrCo}_{0.9} \mathrm{Ir}_{0.1} \mathrm{O}_{3-\delta}$ and Ir metal are comparable with the S-number of $\mathrm{IrO}_{2}$ (by Sigma-Aldrich). The S-number of $\mathrm{IrO}_{2}$ we measured, however, is much lower than that of reported $\mathrm{IrO}_{2}$ (by Alfa-Aesar) ${ }^{41}$. Such higher stability of reported $\mathrm{IrO}_{2}$ can be related to the improved stoichiometry on the surface after additional annealing step. It is likely the production or condition of raw materials may also affect the S-numbers. From these results, we can conclude that the eventually formed Ir-rich layer over $\mathrm{SrCo}_{0.910} \mathrm{Ir}_{0.1} \mathrm{O}_{3-\delta}$ is rather stable if neglecting the initial instability caused by surface reconstruction process.

\section{Discussion}

In summary, we developed a pseudo-cubic $\mathrm{SrCo}_{0.9} \mathrm{Ir}_{0.1} \mathrm{O}_{3-\delta}$ perovskite. Such material can be easily prepared with a simple solid state method without high pressure condition. The Ir from pseudo-cubic $\mathrm{SrCo}_{0.9} \mathrm{Ir}_{0.1} \mathrm{O}_{3-\delta}$ showed an intrinsic activity (TOF) more than two orders of magnitude higher than that in $\mathrm{IrO}_{2}$, and approximately 10 times higher than that in the benchmark PLD$\mathrm{SrIrO}_{3}$. The chemical state of surface $\mathrm{Ir}$ in $\mathrm{SrCo}_{0.9} \mathrm{Ir}_{0.1} \mathrm{O}_{3-\delta}$ is found changed after electrochemical cycling. The reconstructed surfaces are responsible for the observed activities. Although the initial bulk catalysts may not directly influence the OER, this study highlights that the chemical states of bulk catalysts, such as the crystal structure (pseudo-cubic structure with corner-shared IrO6 octahedrons) and the content of oxygen vacancy in the lattice (under-coordinated Ir), will affect the activity of the in-situ formed active sites (Ir-rich surface) for OER.

\section{Methods}

Synthesis of oxides. All composite oxides were synthesized with solid state method. Powders of $\mathrm{SrCO}_{3}, \mathrm{IrO}_{2}, \mathrm{TiO}_{2}$, and $\mathrm{Co}_{3} \mathrm{O}_{4}$ from Sigma-Aldrich Corporation were used as raw materials. Briefly, stoichiometry amount of raw materials were weighted and then mixed in mortar. The mixed precursors were finally calcined with box furnaces in ambient air. A sintering condition of $850^{\circ} \mathrm{C}$ for $12 \mathrm{~h}$, $1100^{\circ} \mathrm{C}$ for $12^{\circ} \mathrm{h}$, and $1200^{\circ} \mathrm{C}$ for $12 \mathrm{~h}$ is applied for $\mathrm{m}-\mathrm{SrIrO}_{3}, \mathrm{SrCo}_{0.9} \mathrm{Ir}_{0.1} \mathrm{O}_{3-\delta}$, and $\mathrm{SrCo}_{0.9} \mathrm{Ti}_{0.1} \mathrm{O}_{3-\delta}$ respectively.

Characterizations. The phase structures of $\mathrm{m}-\mathrm{SrIrO}_{3}$ and $\mathrm{SrCo}_{0.9} \mathrm{Ir}_{0.1} \mathrm{O}_{3-\delta}$ were identified with X-ray Powder Diffractometer (D8 advance, Bruker Corporation). The phase structures were analyzed by the Rietveld method with GSAS program and EXPGUI interface ${ }^{42}$. The morphologies of the materials were studied by FESEM (JEOL 6340F). TEM images were collected on JEM-2010F (JEOL). The XPS tests were performed using a PHI-5400 equipment with $\mathrm{Al} \mathrm{Ka}$ beam source $(250 \mathrm{~W})$ and position-sensitive detector. An XPSpeak41 software is applied for peak fitting. Considering the spin-orbit splitting, a relative area ratio of 2:3 and 3:4 is considered for the doublets in $\mathrm{Sr} \_3 d$ and in $\mathrm{Ir}_{-} 4 f$, respectively. A spin-orbit splitting of $3 \mathrm{eV}$ is considered for the doublets in Ir_4f. A Shirley background was 
applied during the fitting. All peaks are described as convolution of Gaussian and Lorentzian function.

XAS experiments were performed at Singapore Synchrotron Light Source, XAFCA beamline. Data analysis were performed with the Athena software package. The surface areas were characterized by nitrogen adsorption-desorption tests (ASAP Tri-star II 3020) with the BET method.

Electrochemical tests. The electrochemical experiments were carried out on a rotating electrode configuration from Pine Instrument at room temperature. The working electrode of glassy carbon (rotating disk) with an area of $0.196 \mathrm{~cm}^{-2}$ was applied. The catalyst ink with a concentration of $5 \mathrm{mg} \mathrm{mL}^{-1}$ was prepared by ultrasonically dispersing $2.5 \mathrm{mg}$ oxide and $1 \mathrm{mg}$ acetylene black (Alfa Aesar) in an water $(375 \mu \mathrm{L})$-isopropanol $(112.5 \mu \mathrm{L})$-Nafion $(12.5 \mu \mathrm{L})$ solution. $10 \mu \mathrm{L}$ of well dispersed ink was dropped onto the glassy carbon and dried overnight. For ICP-MS tests, the amount of oxide increased to $5 \mathrm{mg}$ for $\mathrm{SrCo}_{0.9} \mathrm{Ir}_{0.1} \mathrm{O}_{3-\delta}$ and $\mathrm{Ir}$ metal. As a higher stability is expected for $\mathrm{IrO}_{2}$, its amount further increase to $10 \mathrm{mg}$. An SP-150 workstation (Bio-Logic Science Instruments) was applied to perform cyclic voltammetry scanning and chronopotentiometric tests. The tests were performed in a $0.1 \mathrm{M} \mathrm{HClO}_{4}$ solution, which was purged with ultra-pure oxygen before each measurement for approximately $30 \mathrm{~min}$. A rotation speed of $1600 \mathrm{rpm}$ was used. A Pt wire was used as the counter electrode and a saturated calomel electrode (SCE) was used as the reference electrode.

TOF calculation. The TOF is calculated from the equation:

$$
\mathrm{TOF}=\frac{j \times A_{\mathrm{OX}}}{4 \times e \times N_{\mathrm{A}}}
$$

where $j$ is the BET surface area normalized current density at an overpotential of $270 \mathrm{mV}$. $A_{\mathrm{OX}}$ is the total surface area of the catalyst deposited on the GC electrode. $e$ is the electric charge carried by a single electron. $N_{\mathrm{A}}$ is the number of Ir atoms. While calculating the $N_{\mathrm{A}}$, three cases are considered.

In the first case, only the Ir atoms from the outermost surface are considered. For $\mathrm{PLD}-\mathrm{SrIrO}_{3}$, the calculation is performed by assuming $\mathrm{PLD}-\mathrm{SrIrO}_{3}$ with an ideal P $m-3 m$ structure and a perfect (100) surface. A lattice parameter of $4.024 \AA$ reported in the literature is used ${ }^{13}$. For $\mathrm{m}_{-} \mathrm{SrIrO}_{3}$, the lattice parameters from XRD refinement are used and a (001) surface, with the highest Ir surface density, is chosen (thus the activity will not be overestimated). For $\mathrm{SrCo}_{0.9} \mathrm{Ir}_{0.1} \mathrm{O}_{3-\delta}$, the lattice parameters from XRD refinement are used and a (010) surface, with the highest Ir surface density, is chosen (thus the activity will not be overestimated). For $\operatorname{IrO}_{2}$, lattice parameters of $a=4.505 \AA$ and $c=3.159 \AA$ are used and a (110) surface is considered $^{43}$. In this case, the active Ir atoms in reconstructed surface region are not counted and thus the activity is over-estimated. Thus, this way cannot be used for comparing TOF.

In the second case, all Ir atoms for each catalyst loaded on the electrode are considered active for OER. Please note this case over-estimates the active Ir atoms and thus the activity will be significantly under-estimated. Therefore, this way does not make sense, too.

In the third case, to include the effect of surface reconstruction, all Ir atoms from reconstructed surface regions are considered. Based on the TEM results (Fig. 2a, c), we assume the depth of the reconstructed surface region in $\mathrm{m}-\mathrm{SrIrO}_{3}$ and $\mathrm{SrCo}_{0.9} \mathrm{Ir}_{0.1} \mathrm{O}_{3-\delta}$ is 5 and $10 \mathrm{~nm}$, respectively. In $\mathrm{PLD}-\mathrm{SrIrO}_{3}$ film, it was reported that the root mean square roughness is $<4 \mathrm{~nm}$ before OER and $<20 \mathrm{~nm}$ after cycling ${ }^{13}$. Thus, we assume a surface reconstruction with a depth of 8 and $40 \mathrm{~nm}$ to normalize the initial activity and final activity (after $30 \mathrm{~h}$ test) of Ir in PLD-SrIrO 3 , respectively. For $\mathrm{IrO}_{2}$, the surface reconstruction effect is negligible, and thus is not considered.

Estimation of the current due to Sr and Co leaching. Here, we estimate the maximum current contributed by $\mathrm{Sr}$ and Co leaching (possible leaching current). Several assumptions are made for the calculation/estimation:

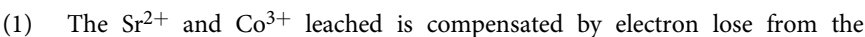
catalyst, i.e., all leached $\mathrm{Sr}^{2+}$ and $\mathrm{Co}^{3+}$ cations will contribute to the current.

(2) All $\mathrm{Sr}^{2+}$ and $\mathrm{Co}^{3+}$ from the surface region $(10 \mathrm{~nm}$ depth, determined by TEM as shown in the manuscript) leached in 5 cycles at a constant speed. This is because we did not see steep current changes due to cation leaching. Then, the current from cation leaching $\left(I_{\mathrm{ox}}^{\text {leach }}\right)$ can be calculated by the equation:

$$
I_{\mathrm{ox}}^{\text {leach }}=\frac{\left(2 \times n_{\mathrm{Sr}^{2+}}+3 \times n_{\mathrm{C}^{3+}}\right) \times e}{t * S_{\mathrm{ox}}}
$$

$n_{\mathrm{Sr}^{2+}}$ and $n_{\mathrm{Co}^{3+}}$ are the number of leached $\mathrm{Sr}^{2+}$ and $\mathrm{Co}^{3+}$ from the surface region $(10 \mathrm{~nm}$ depth). $e$ is the electric charge of an electron. $t$ is the time used for 5 cycles. Our cycling test for $\mathrm{SrCo}_{0.9} \mathrm{Ir}_{0.1} \mathrm{O}_{3-\delta}$ is performed in the potential range (vs. RHE) from 1 to $1.7 \mathrm{~V}$. The scan rate is $10 \mathrm{mV} \mathrm{s}^{-1}$. $S_{o x}$ is the surface area of the loaded catalyst.

Based on that, a maximum current of $0.0186 \mathrm{~mA} \mathrm{~cm}_{\text {ox }}^{-2}$ is calculated, and which can contribute to the measured current in initial 5 cycles. This current value is more than two orders of magnitude lower than the measured OER current from $\mathrm{SrCo}_{0.9} \mathrm{Ir}_{0.1} \mathrm{O}_{3-\delta}$. For example, at an overpotential of 270 and $320 \mathrm{mV}$, the measured OER current from $\mathrm{SrCo}_{0.9} \mathrm{Ir}_{0.1} \mathrm{O}_{3-\delta}$ can reach 2.8 and $16.3 \mathrm{~mA} \mathrm{~cm}-2$, respectively.

DFT calculation. Spin-polarized DFT calculations were performed using the Vienna ab initio simulation package (VASP) ${ }^{44,45}$ with the projector-augmented wave (PAW) approach ${ }^{46}$ and the Perdew-Burk-Ernzerhof (PBE) exchangecorrelation functional ${ }^{47}$. To account for the strongly localized $d$-electrons of $\mathrm{Co}$, a $\mathrm{DFT}+\mathrm{U}$ approach was adopted and an effective Hubbard $\mathrm{U}$ parameter of $3.32 \mathrm{eV}$ was used ${ }^{48,49}$. The electronic energy tolerance was set to $10^{-6} \mathrm{eV}$ and the force tolerance for structural relaxation was $0.015 \mathrm{eV} \AA^{-1}$. The structural model for PLD- $\mathrm{SrIrO}_{3}$ is a $2 \times 2 \times 2$ cubic supercell, for $\mathrm{m}-\mathrm{SrIrO}_{3}$ is a conventional standard unit cell and for pc-SrCo ${ }_{0.875} \mathrm{Ir}_{0.125} \mathrm{O}_{3}$ is a $2 \times 1 \times 1$ orthorhombic supercell. For all compositions, the lattice constants and ion positions were first fully relaxed. Then, the defect calculations were performed on the fully relaxed stoichiometric structures, and all the symmetry distinct oxygen sites in the corresponding model were explored to search for the most stable vacancy site. The oxygen vacancy concentration for PLD-SrIrO 3 and pc- $\mathrm{SrCo}_{0.875} \mathrm{Ir}_{0.125} \mathrm{O}_{3}$ is $4.167 \%$ while for $\mathrm{m}$-SrIrO is $3.125 \%$. The total energy calculations of all structures were performed with the tetrahedron method with Blöchl corrections ${ }^{50}$ and an energy cutoff of $520 \mathrm{eV}$. And a $6 \times 6 \times 6$ Monkhorst-Pack k-point mesh was employed for PLD-SrIrO ${ }_{3}$, a $4 \times 6 \times$ 8 mesh for $\mathrm{pc}^{-} \mathrm{SrCo}_{0.875} \mathrm{Ir}_{0.125} \mathrm{O}_{3}$ and a $10 \times 6 \times 4$ mesh for $\mathrm{m}-\mathrm{SrIrO}_{3}$. For all compositions, the bulk oxygen vacancy formation energy was calculated based on the most stable oxygen-deficient structure and with respect to $\mathrm{H}_{2} \mathrm{O}(\mathrm{g})$ and $\mathrm{H}_{2}(\mathrm{~g})$ at standard condition. The oxygen vacancy formation enthalpy will be shifted around $+2.33 \mathrm{eV}$ larger if $\mathrm{O}_{2}(\mathrm{~g})$ is used as the reference.

\section{Data availability}

All relevant data are available from the authors upon request.

Received: 1 June 2018 Accepted: 16 January 2019

Published online: 04 February 2019

\section{References}

1. Ginley, D., Green, M. A. \& Collins, R. Solar energy conversion toward 1 terawatt. MRS Bull. 33, 355-364 (2008).

2. Strmcnik, D. et al. Improving the hydrogen oxidation reaction rate by promotion of hydroxyl adsorption. Nat. Chem. 5, 300-306 (2013).

3. Danilovic, N. et al. Enhancing the alkaline hydrogen evolution reaction activity through the bifunctionality of $\mathrm{Ni}(\mathrm{OH})_{2} /$ metal catalysts. Angew. Chem. Int. Ed. 51, 12495-12498 (2012)

4. Reier, T., Oezaslan, M. \& Strasser, P. Electrocatalytic oxygen evolution reaction (OER) on $\mathrm{Ru}, \mathrm{Ir}$, and Pt catalysts: a comparative study of nanoparticles and bulk materials. ACS Catal. 2, 1765-1772 (2012).

5. Antolini, E. Iridium as catalyst and cocatalyst for oxygen evolution/reduction in acidic polymer electrolyte membrane electrolyzers and fuel cells. ACS Catal. 4, 1426-1440 (2014).

6. Zhao, Y. X., Hernandez-Pagan, E. A., Vargas-Barbosa, N. M., Dysart, J. L. \& Mallouk, T. E. A high yield synthesis of ligand-free iridium oxide nanoparticles with high electrocatalytic activity. J. Phys. Chem. Lett. 2, 402-406 (2011).

7. Lee, Y., Suntivich, J., May, K. J., Perry, E. E. \& Shao-Horn, Y. Synthesis and activities of rutile $\mathrm{IrO}_{2}$ and $\mathrm{RuO}_{2}$ nanoparticles for oxygen evolution in acid and alkaline solutions. J. Phys. Chem. Lett. 3, 399-404 (2012).

8. Lim, J. et al. Ultrathin $\mathrm{IrO}_{2}$ nanoneedles for electrochemical water oxidation Adv. Funct. Mater. 28, 1704796 (2018).

9. Pi, Y. C., Zhang, N., Guo, S. J., Guo, J. \& Huang, X. Q. Ultrathin laminar Ir superstructure as highly efficient oxygen evolution electrocatalyst in broad $\mathrm{pH}$ range. Nano Lett. 16, 4424-4430 (2016).

10. Oh, H. S., Nong, H. N., Reier, T., Gliech, M. \& Strasser, P. Oxide-supported Ir nanodendrites with high activity and durability for the oxygen evolution reaction in acid PEM water electrolyzers. Chem. Sci. 6, 3321-3328 (2015).

11. Nong, H. N. et al. Oxide-supported $\mathrm{IrNiO}_{x}$ core-shell particles as efficient, cost-effective, and stable catalysts for electrochemical water splitting. Angew. Chem. Int. Ed. 54, 2975-2979 (2015).

12. Diaz-Morales, O. et al. Iridium-based double perovskites for efficient water oxidation in acid media. Nat. Commun. 7, 12363 (2016).

13. Seitz, L. C. et al. A highly active and stable $\mathrm{IrO}_{x} / \mathrm{SrIrO}_{3}$ catalyst for the oxygen evolution reaction. Science 353, 1011-1014 (2016).

14. Tang, R. B. et al. Oxygen evolution reaction electrocatalysis on $\mathrm{SrIrO}_{3}$ grown using molecular beam epitaxy. J. Mater. Chem. A 4, 6831-6836 (2016).

15. Grimaud, A. et al. Activation of surface oxygen sites on an iridium-based model catalyst for the oxygen evolution reaction. Nat. Energy 2, 16189 (2017). 
16. Liu, Y. X., Masumoto, H. \& Goto, T. Structural, electrical and optical characterization of $\mathrm{SrIrO}_{3}$ thin films prepared by laser-ablation. Mater. Trans. 46, 100-104 (2005).

17. Zhao, J. G. et al. High-pressure synthesis of orthorhombic $\mathrm{SrIrO}_{3}$ perovskite and its positive magnetoresistance. J. Appl. Phys. 103, 103706 (2008).

18. Longo, J. M., Kafalas, J. A. \& Arnott, R. J. Structure and properties of high and low pressure forms of $\mathrm{SrIrO}_{3}$. J. Solid State Chem. 3, 174-179 (1971)

19. Qasim, I., Kennedy, B. J. \& Avdeev, M. Synthesis, structures and properties of transition metal doped $\mathrm{SrIrO}_{3}$. J. Mater. Chem. A 1, 3127-3132 (2013).

20. Sun, S. N., Li, H. Y. \& Xu, Z. C. J. Impact of surface area in evaluation of catalyst activity. Joule 2, 1024-1027 (2018).

21. Danilovic, N. et al. Using surface segregation to design stable Ru-Ir oxides for the oxygen evolution reaction in acidic environments. Angew. Chem. Int. Ed. 53, 14016-14021 (2014).

22. Massue, C. et al. Microwave-assisted synthesis of stable and highly active Ir oxohydroxides for electrochemical oxidation of water. ChemSusChem $\mathbf{1 0}$, 1958-1968 (2017).

23. Willinger, E., Massue, C., Schlogl, R. \& Willinger, M. G. Identifying key structural features of $\mathrm{IrO}_{x}$ water splitting catalysts. J. Am. Chem. Soc. 139, 12093-12101 (2017).

24. Mutoro, E., Crumlin, E. J., Biegalski, M. D., Christen, H. M. \& Shao-Horn, Y. Enhanced oxygen reduction activity on surface-decorated perovskite thin films for solid oxide fuel cells. Energy Environ. Sci. 4, 3689-3696 (2011).

25. Vasquez, R. P. X-ray photoelectron-spectroscopy study of $\mathrm{Sr}$ and $\mathrm{Ba}$ compounds. J. Electron Spectrosc. 56, 217-240 (1991).

26. Wertheim, G. K. \& Guggenheim, H. J. Conduction-electron screening in metallic oxides- $\mathrm{IrO}_{2}$. Phys. Rev. B 22, 4680-4683 (1980).

27. Pfeifer, V. et al. The electronic structure of iridium oxide electrodes active in water splitting. Phys. Chem. Chem. Phys. 18, 2292-2296 (2016).

28. Atanasoska, L., Atanasoski, R. \& Trasatti, S. XPS and AES study of mixed layers of $\mathrm{RuO}_{2}$ and $\mathrm{IrO}_{2}$. Vacuum 40, 91-94 (1990).

29. Kodintsev, I. M., Trasatti, S., Rubel, M., Wieckowski, A. \& Kaufher, N. X-ray photoelectron-spectroscopy and electrochemical surface characterization of $\mathrm{IrO}_{2}+\mathrm{RuO}_{2}$ electrodes. Langmuir 8, 283-290 (1992).

30. Peuckert, M. XPS study on thermally and electrochemically prepared oxidic adlayers on iridium. Surf. Sci. 144, 451-464 (1984).

31. Minguzzi, A. et al. Easy accommodation of different oxidation states in iridium oxide nanoparticles with different hydration degree as water oxidation electrocatalysts. ACS Catal. 5, 5104-5115 (2015).

32. Smith, R. D. L., Sporinova, B., Fagan, R. D., Trudel, S. \& Berlinguette, C. P. Facile photochemical preparation of amorphous iridium oxide films for water oxidation catalysis. Chem. Mater. 26, 1654-1659 (2014).

33. Pfeifer, V. et al. The electronic structure of iridium and its oxides. Surf. Interface Anal. 48, 261-273 (2016)

34. $\mathrm{Li}$, T. et al. Atomic-scale insights into surface species of electrocatalysts in three dimensions. Nat. Catal. 1, 300-305 (2018).

35. Minguzzi, A. et al. Observing the oxidation state turnover in heterogeneous iridium-based water oxidation catalysts. Chem. Sci. 5, 3591-3597 (2014).

36. Wang, H. Y. et al. In operando identification of geometrical-site-dependent water oxidation activity of spinel $\mathrm{Co}_{3} \mathrm{O}_{4}$. J. Am. Chem. Soc. 138, 36-39 (2016).

37. Mefford, J. T. et al. Water electrolysis on $\mathrm{La}_{1-x} \mathrm{Sr}_{x} \mathrm{CoO}_{3 \text {-delta }}$ perovskite electrocatalysts. Nat. Commun. 7, 11053 (2016)

38. Lee, Y. L., Kleis, J., Rossmeisl, J., Shao-Horn, Y. \& Morgan, D. Prediction of solid oxide fuel cell cathode activity with first-principles descriptors. Energy Environ. Sci. 4, 3966-3970 (2011).

39. Tejuca, L. G., Bell, A. T., Fierro, J. L. G. \& Pena, M. A. Surface behavior of reduced $\mathrm{LaCoO}_{3}$ as studied by TPD of $\mathrm{CO}, \mathrm{CO}_{2}$ and $\mathrm{H}_{2}$ probes and by XPS. Appl. Surf. Sci. 31, 301-316 (1988).

40. Pishahang, M., Bakken, E., Stolen, S., Larring, Y. \& Thomas, C. I. Oxygen nonstoichiometry and redox thermodynamics of $\mathrm{LaMn}_{1-x} \mathrm{Co}_{x} \mathrm{O}_{3 \text {-delta. Solid State }}$ Ion. 231, 49-57 (2013).

41. Geiger, S. et al. The stability number as a metric for electrocatalyst stability benchmarking. Nat. Catal. 1, 508-515 (2018).

42. Toby, B. H. EXPGUI, a graphical user interface for GSAS. J. Appl. Crystallogr. 34, 210-213 (2001).

43. Sen, F. G. et al. Towards accurate prediction of catalytic activity in $\mathrm{IrO}_{2}$ nanoclusters via first principles-based variable charge force field. J. Mater. Chem. A 3, 18970-18982 (2015).
44. Kresse, G. \& Furthmuller, J. Efficient iterative schemes for ab initio totalenergy calculations using a plane-wave basis set. Phys. Rev. B 54, 11169-11186 (1996).

45. Kresse, G. \& Furthmuller, J. Efficiency of ab-initio total energy calculations for metals and semiconductors using a plane-wave basis set. Comput. Mater. Sci. 6, 15-50 (1996).

46. Blochl, P. E. Projector augmented-wave method. Phys. Rev. B 50, 17953-17979 (1994).

47. Perdew, J. P., Burke, K. \& Ernzerhof, M. Generalized gradient approximation made simple. Phys. Rev. Lett. 77, 3865-3868 (1996).

48. Wang, L., Maxisch, T. \& Ceder, G. Oxidation energies of transition metal oxides within the GGA $+\mathrm{U}$ framework. Phys. Rev. B 73, 195107 (2006).

49. Lee, Y. L., Kleis, J., Rossmeisl, J. \& Morgan, D. Ab initio energetics of $\mathrm{LaBO}_{3}(001)(\mathrm{B}=\mathrm{Mn}, \mathrm{Fe}, \mathrm{Co}$, and Ni) for solid oxide fuel cell cathodes. Phys. Rev. B 80, 224101 (2009).

50. Blochl, P. E., Jepsen, O. \& Andersen, O. K. Improved tetrahedron method for Brillouin-zone integrations. Phys. Rev. B 49, 16223-16233 (1994).

\section{Acknowledgements}

This work is supported by the Singapore MOE Tier 2 (MOE2017-T2-1-009) and by the Singapore National Research Foundation under its Campus for Research Excellence And Technological Enterprise (CREATE) programme, through the Singapore Berkeley Research Initiative for Sustainable Energy (SinBeRISE), The Cambridge Center for Carbon Reduction in Chemical Technology $(\mathrm{C} 4 \mathrm{~T})$, and $\mathrm{eCO}_{2} \mathrm{EP}$ programmes. The authors thank the Facility for Analysis, Characterisation, Testing and Simulation (FACTS) in Nanyang Technological University for materials characterization.

\section{Author contributions}

Y.C. and Z.J.X. designed the experiments. Y.C. conducted material synthesis, performed $\mathrm{XRD}$ analysis, and electrochemical characterization and analysis. H.L. and Y.S. performed DFT calculations. J.W. and Y.C. performed TEM experiments and analysis. Y.D., S.X. and Y.C. carried out XAS experiment and analysis. Y.C. and Z.J.X. wrote the manuscript. M.S., J.W.A. and A.C.F. analyzed the data and polished the manuscript.

\section{Additional information}

Supplementary Information accompanies this paper at https://doi.org/10.1038/s41467 019-08532-3.

Competing interests: The authors declare no competing interests.

Reprints and permission information is available online at http://npg.nature.com/ reprintsandpermissions/

Journal peer review information: Nature Communications thanks the anonymous reviewers for their contribution to the peer review of this work.

Publisher's note: Springer Nature remains neutral with regard to jurisdictional claims in published maps and institutional affiliations.

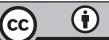

Open Access This article is licensed under a Creative Commons Attribution 4.0 International License, which permits use, sharing, adaptation, distribution and reproduction in any medium or format, as long as you give appropriate credit to the original author(s) and the source, provide a link to the Creative Commons license, and indicate if changes were made. The images or other third party material in this article are included in the article's Creative Commons license, unless indicated otherwise in a credit line to the material. If material is not included in the article's Creative Commons license and your intended use is not permitted by statutory regulation or exceeds the permitted use, you will need to obtain permission directly from the copyright holder. To view a copy of this license, visit http://creativecommons.org/ licenses/by/4.0/.

(C) The Author(s) 2019 